\title{
On the Accuracy of Total-IBA
}

\author{
C.Jeynes $^{1 *}$, V.V.Palitsin ${ }^{1}$, M.Kokkoris ${ }^{3}$, A.Hamilton, ${ }^{2}$ G.W.Grime ${ }^{1}$ \\ 1. University of Surrey Ion Beam Centre, Guildford, England \\ 2. Civil and Environmental Engineering, University of Strathclyde, Glasgow, Scotland \\ 3. Department of Physics, National Technical University of Athens, Greece
}

\begin{abstract}
"Total-IBA" implies the synergistic use of multiple IBA techniques. It has been claimed that Total-IBA inherits the accuracy of the most accurate IBA technique used. A specific example is now given of this where (in vacuo) EBS/PIXE of a glass sample uniform in depth is validated against absolutely calibrated EPMA of the same sample. The EPMA results had a mass closure gap of $2.0 \pm 0.6 \mathrm{wt} \%$; the full PIXE analysis determined the composition of this missing $2 \mathrm{wt} \%$. The PIXE calibration was against a single certified glass sample, with uncertainties per line $\sim 10 \%$.

Benchmarking also demonstrates $\sim 10 \%$ underestimation of the Si scattering cross-section at proton energies $\sim 3 \mathrm{MeV}$. But the Total-IBA determination of the silica content had a low standard uncertainty of about $2 \%$. This is due to the strong constraints of both the chemical prior and also the mass closure properties of the EBS. Irradiation-induced sodium migration in this soda-lime glass is explored.
\end{abstract}

Keywords: Ion Beam Analysis, particle-induced X-ray emission, elastic backscattering, RBS, SEM-WDX, XRF, Na migration, precision, benchmark, Rosslyn Chapel

\section{Introduction}

Ion Beam Analysis (IBA) typically uses MeV light ion beams to probe the elemental composition of the near-surfaces of materials. ${ }^{1}$ Such energetic ion beams can excite the atoms of the target, yielding the characteristic X-rays also excited by primary beams of electrons or photons. Photon excitation is termed X-ray fluorescence (XRF). Here we directly compare particle-induced X-ray emission (PIXE) and the electron-induced X-ray emission generated in an SEM (a scanning electron microscope), analysed in this case by a wavelength-dispersive spectrometer (WDX: PIXE usually utilises an energydispersive spectrometer-EDX). SEM-WDX is also often referred to as electron-probe microanalysis (EPMA) when the instrument includes multiple WDX spectrometers.

But $\mathrm{MeV}$ ion beams can also excite the atomic nuclei, either elastically giving so-called "elastic backscattering spectrometry" (EBS), or inelastically giving "nuclear reaction analysis" (NRA) which does not concern us here. A variety of NRA is particle-induced gamma-emission (PIGE): gamma spectroscopy has been central to the determination of nuclear energy levels, and remains important for IBA (especially for ${ }^{19} \mathrm{~F}$ and ${ }^{23} \mathrm{Na}$ ).

"Rutherford backscattering spectrometry" (RBS) is a special case of EBS where the scattering crosssection is approximated analytically by considering point charges in a screened Coulomb field. This approximation is very good for $1.5 \mathrm{MeV}^{4} \mathrm{He}$ beams (for example) because the screening correction is quite accurately known for such beams. ${ }^{2}$ The intrinsic accuracy of RBS has been exploited to demonstrate it as a primary reference method for non-destructively determining quantity of material in thin films at unsurpassed accuracy. ${ }^{3}$ RBS has already been used in the determination of Ga photoionisation cross-sections at high traceable accuracy by Unterumsberger et al. $(2018)^{4}$ who also determine other XRF Fundamental Parameters, saying :-

XRF quantification can be absolute through proper modelling of the physics since X-ray ionization and absorption processes are well-understood: this method requires detailed knowledge of the Fundamental Parameters and has been in use since the 1980s for all the XRF methods, including EPMA and PIXE. 
Total-IBA ${ }^{5}$ is the synergistic use of multiple IBA methods, most usually EBS and PIXE since EBS is very sensitive to the depth of the atom in the sample but rather insensitive to atomic mass and PIXE is very sensitive to atomic number but rather insensitive to depth (although differential PIXE methods can be used to obtain useful depth information, especially for samples too thick for EBS: for a recent discussion see for example Šmit \& Holc ${ }^{6}$; such methods both have relatively poor depth resolution, and also are time consuming since multiple measurements must be made at different geometries or beam energies).

The power of Total-IBA is that complex samples may be analysed where the PIXE and EBS signals are individually intractable (the samples cannot be solved using either PIXE or EBS alone): at present there is only one code (the DataFurnace code ${ }^{7}$ ) capable of handling such cases efficiently (the MultiSIMNRA $\operatorname{code}^{8}$ can do Total-IBA but cannot at present handle PIXE data). It seems evident that accuracy should be conserved in a synergistic analysis, but this has not until now been demonstrated unequivocally for IBA. This work is a first attempt to assign good estimates of uncertainty to such an analysis.

The present work simply obtains the composition of a homogeneous glass by (in vacuo) Total-IBA, and is part of a wider study for conservation purposes of the historic glass from the Rosslyn Chapel. ${ }^{9}$ This wider study used an external beam analysis of as-received (inhomogeneous) glass samples which will be reported elsewhere. Such an analysis is now standard where PIXE and PIGE are used (but not EBS; see for example Calligaro $2008^{10}$, and Hunault et al. $2017^{11}$ ). Analytically, the sample structure is trivially simple (uniform) but the glass is chemically complex, having 16 independently measurable elements, which can nevertheless be determined without prior assumptions by IBA (see Analytical Protocol).

After describing the experimental and analytical Methods, including a detailed discussion of the particle scattering cross-section data used, and after a digression on the measurement of sodium in glasses despite its well-known Mobility under irradiation, we give a detailed account of the Calibration of a Total-IBA system together with a discussion of the analytical Protocol for this case. Calibration is central to all accurate analysis and is usually taken for granted in "mature" techniques like IBA. But in fact there are no standard (published) protocols for accurate IBA (except the protocol local to Surrey established under ISO 17025 for the measurement of Quantity of Material by RBS [ref.3]), in contrast to the detailed standards now available for modern workhorse analytical methods (for example, those for DESI-MS ${ }^{12}$, SIMS ${ }^{13}$ and XPS ${ }^{14}$ established under the aegis of VAMAS). The Results are presented in some detail, since for this very simple sample it is only the details that are interesting. In particular we present new Benchmarking results that significantly affect the interpretation of the EBS. We can then properly present the estimates of Uncertainty, and comment on the properties of Mass Closure that yield greatly reduced uncertainty. The Discussion leads to extended Conclusions which expand significantly on the summary in the Abstract.

\section{Experimental and Analytical Details}

The sample analysed was a piece of glass about $3 \mathrm{~mm}$ thick from the Rosslyn Chapel. It was crosssectioned at Glasgow University (embedded in a circular resin block and polished) and analysed by EPMA using a JEOL JXA-8530F and its proprietary software ${ }^{15}$. The sample was about $3 \times 5 \mathrm{~mm}^{2}$, and was analysed using $20 \mathrm{keV}$ in 10 spots distributed along the sample centre line, with an electron current of $20 \mathrm{nA}\left(1 / 4 \mathrm{~mA} / \mathrm{cm}^{2}\right.$ using a spot size defocussed to 100 microns $)$ verified to avoid Na migration within the $60 \mathrm{~s}$ measurement time. The $\mathrm{O}$ and $\mathrm{S}$ signals were not measured, and the WDX detectors were calibrated against Albite $\left(\mathrm{Na}_{2} \mathrm{O}\right)$, Wollastonite $\left(\mathrm{SiO}_{2} \& \mathrm{CaO}\right)$, Corundum $\left(\mathrm{Al}_{2} \mathrm{O}_{3}\right)$, Orthoclase $\left(\mathrm{K}_{2} \mathrm{O}\right)$, and $\mathrm{Fe}\left(\mathrm{Fe}_{2} \mathrm{O}_{3}\right) .60 \mathrm{~s}$ peak measurements were made, with two corresponding $30 \mathrm{~s}$ background measurements each side of the peak.

Quantification was carried out using the instrument's built-in software, including the ZAF correction algorithm (that is, the correction for atomic number, self-absorption, self-fluorescence). The ZAF 
correction was obtained explicitly per line for each EPMA analysis: the " $F$ " (fluorescence) correction is negligible in the Rosslyn glass analysis for all lines except $\mathrm{Si}(1 / 4 \%)$ and $\mathrm{Na}(<1 / 2 \%)$. The PIXE code GUPIX $^{16}$ (which does not implement the general case of layered samples) of course implements the fluorescence correction; but the Total-IBA code DataFurnace ${ }^{17}$ does not implement it, since it is nontrivial to do it correctly for the general case and anyway it is usually very small (as in this case).

Total-IBA with a proton beam of various energies around $3 \mathrm{MeV}$ was done at Surrey University on the cross-sectioned sample using a standard microbeam vacuum chamber ${ }^{18}$ but a redesigned beamline. The beamline components are mounted on a continuous length of a high stiffness aluminium extrusion supported on synthetic granite blocks. The object apertures are formed by Electrical Discharge Machining cut-outs in the polished edges of $150 \mu \mathrm{m}$ high purity tantalum foils. The object apertures are rectangular with aspect ratio 4:1 matching the XY demagnification factors of the focussing system: sizes range from $(2 \times 1 / 2) \mathrm{mm}$ down to $(80 \times 20) \mu \mathrm{m}$. Circular collimator apertures were made in tantalum foil by precision micromachining and the edges cleaned using a high current FIB (focussed ion beam) technique. Motorised ladders accept 10 apertures for easy size selection. Thermal loads are reduced by water-cooled motorised beam dump slits before the apertures. A Wien filter ${ }^{19}$ is installed in the object space of the beamline to reduce the aperture's edge-scattering halo.

A new nuclear microprobe system uses a spaced triplet configuration of Oxford Microbeams OM-50 quadrupoles in which the spacing of the first two lenses can be easily adjusted. This was designed using WinTRAX simulations ${ }^{20}$ and enables routine submicron spatial resolution for $2.5 \mathrm{MeV}$ protons and beam currents $\sim 1 \mathrm{nA}$. The separation of the first two quadrupoles in the Oxford triplet results in increased demagnification and optimum acceptance. After an extensive assessment a single spaced Oxford triplet configuration was chosen, that is, the first and the second lenses are placed apart with spacing of one quadrupole length with calculated XY demagnifications of $87 \times 25$.

A PIXE detector (in the IBM geometry) and a particle detector (in the Cornell geometry) are both at backward angles to the beam of respectively $135^{\circ}, 155^{\circ}$; with solid angles respectively $18,41.4 \mathrm{msr}$. The PIXE detector is a $\mathrm{Si}(\mathrm{Li})$, with a $12.5 \mu \mathrm{m}$ Duraberyllium entrance window and a (nominally) $125 \mu \mathrm{m}$ pure Be filter to stop scattered protons. The beam is focussed to $\sim 2 \mu \mathrm{m}$ diameter and scanned over a defined area (here usually $1 / 2 \mathrm{~mm}$ square). A lead-glass certified standard $\left(\mathrm{BCR} 126 \mathrm{~A}^{21}\right.$ ) was used to obtain the Xray detector effective solid angle (from the $\mathrm{Pb} \mathrm{L} \alpha$ line) and the filter thickness (from the $\mathrm{Si} \mathrm{K \alpha}$ line).

\begin{tabular}{|c|c|c|c|c|c|c|c|c|c|c|}
\hline \multicolumn{2}{|c|}{ OMDAQ } & \multirow[t]{2}{*}{ Sample } & \multirow{2}{*}{$\begin{array}{c}\text { energy } \\
\text { keV }\end{array}$} & \multirow{2}{*}{$\begin{array}{c}\text { time } \\
\mathrm{s}\end{array}$} & \multicolumn{2}{|c|}{$\operatorname{scan}(\mu \mathrm{m})$} & \multirow{2}{*}{$\begin{array}{c}\text { charge } \\
\mathrm{nC}\end{array}$} & \multicolumn{2}{|c|}{ current ( $p A)$} & \multirow{2}{*}{$\begin{array}{c}\text { flux } \\
\underline{\mathrm{p} A} / \mu \mathrm{m}^{2}\end{array}$} \\
\hline$\#$ & date & & & & $x$ & $Y$ & & average & measured & \\
\hline 989009 & 14 Dec & BCR glass & 2734 & 226 & 250 & 250 & 62 & 274 & 300 & 0.004 \\
\hline 989010 & $14 \mathrm{Dec}$ & BCR glass & 3066 & 416 & 75 & 75 & 52 & 125 & 150 & 0.022 \\
\hline 989012 & 14 Dec & Rosslyn glass & 2827 & 1808 & 75 & 75 & 1696 & 938 & 800 & 0.167 \\
\hline 989013 & 14 Dec & Rosslyn glass & 2827 & 1810 & 5 & 5 & 1419 & 784 & & 31.359 \\
\hline 989014 & 14 Dec & Rosslyn glass & 2827 & 1784 & 2 & 2 & 1271 & 712 & & 178.111 \\
\hline 989020 & $15 \mathrm{Dec}$ & Rosslyn glass & 3080 & 7211 & 500 & 2 & 115 & 16 & & 0.016 \\
\hline
\end{tabular}

Table 1: Measurement conditions

Data collected (in vacuum) 14, 15 December 2018. Nominal beam incidence normal on samples. 2 detectors (PIXE \& EBS) respectively with solid angles $18,41.4 \mathrm{msr}$, and at angles to the beam $135^{\circ}, 155^{\circ}$.

The accelerator is a 2 MV HVEE Tandetron, with generating voltmeter (GVM) energy stabilisation; a GVM factor calibrating the nominal terminal voltage of 1.00011(4) is here measured directly using the very well-established $2663 \pm 7 \mathrm{keV}$ resonance in the ${ }^{16} \mathrm{O}(\mathrm{p}, \mathrm{p}){ }^{16} \mathrm{O}$ cross-section function (with the method of Colaux et al, ${ }^{22}$ see Figure $\mathbf{3 b}$ below). This resonance energy is accurately known, with an uncertainty given in the compilations. ${ }^{23}$ It has long been of great interest ${ }^{24}$ and was accurately determined over 50 years ago. ${ }^{25}$ 
OMDAQ-3 ${ }^{26}\left(16,16 \mathrm{X}\right.$; version $3.2 .3 .884,20^{\text {th }}$ Nov 2018) was used both to collect the data and to interpret the datasets. DataFurnace ${ }^{27}$ (NDFv10.0 rev.28/2/2019 and WiNDFv9.3.98) was used to fit EBS/PIXE data. GUPIX [ref.16] was used to extract the characteristic X-ray peak areas (from the PIXE spectra) required as input to DataFurnace. GUPIX corrects these peak areas for pileup and line overlaps (including escape peaks). The use of NDF for PIXE was described in Pascual-Izarra et $_{\text {al. }}{ }^{28}$ PIGE is supported by NDF but is not needed here. ${ }^{29}$ SRIM 2003 stopping powers ${ }^{30}$ were used (later versions of SRIM have not changed the values noticeably). Pulse pileup was calculated for the particle detector using the algorithm of Wielopolsky \& Gardner. ${ }^{31}$

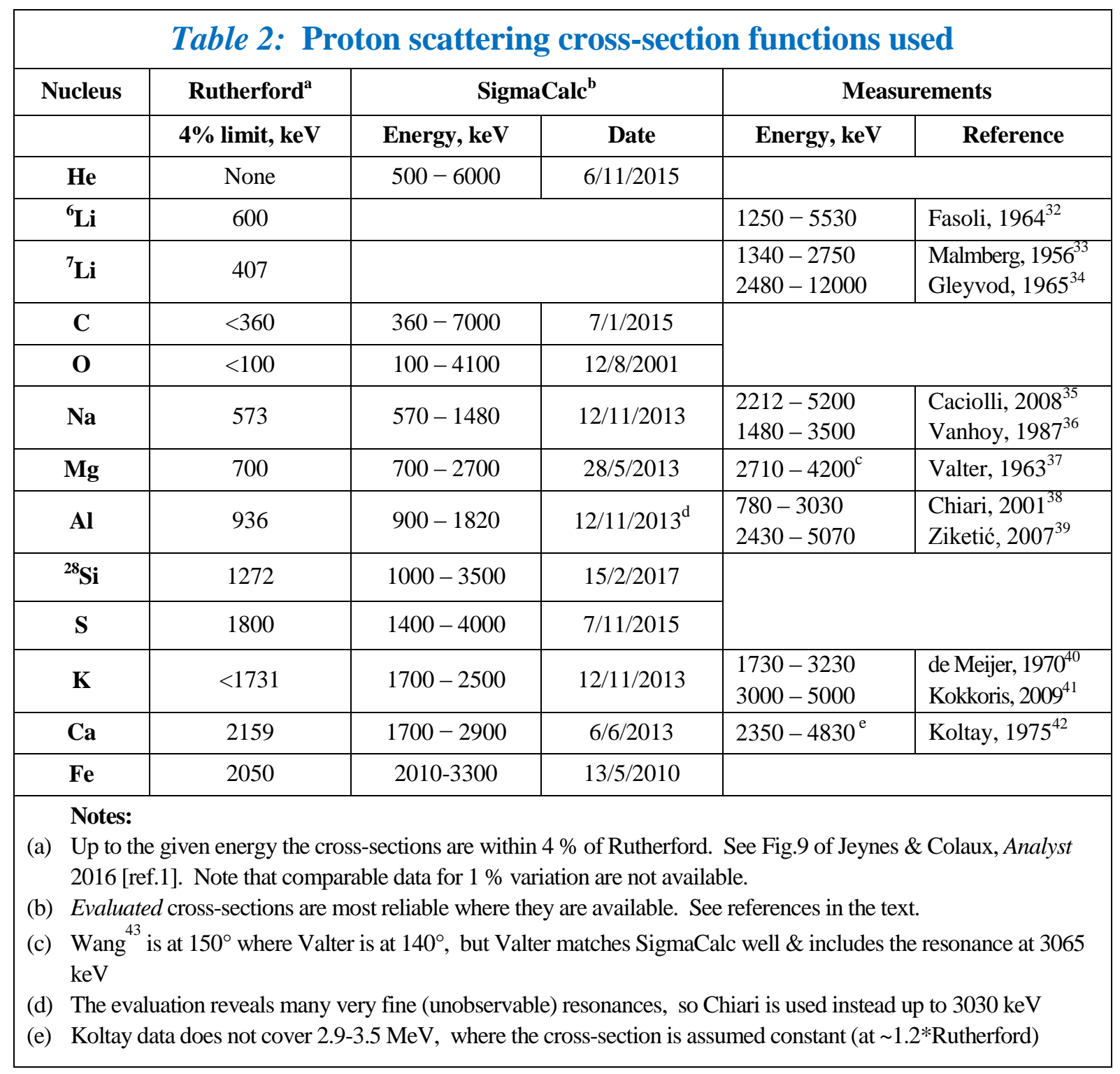

Robustified ${ }^{44}$ chi-squared ("pseudo- $\chi^{2}$ ") fitting is used to fit PIXE line areas self-consistently with EBS spectra. This is needed because a) the chi-squared function is mathematically rather poorly behaved for poor fits, and b) PIXE data is introduced into NDF as line areas, which have a different statistical behaviour from spectral data and for which the chi-squared minimisation procedure is not strictly valid. In this work extensive use of "logical elements" $\left(\mathrm{SiO}_{2}\right.$ and other oxides) was made to impose chemical constraints ${ }^{45}$ on the fitting.

This work analyses 6 datasets (\#\#09, 10, 12, 13, 14, 20) whose analytical conditions are given in Table 1. The particle detector is large $\left(100 \mathrm{~mm}^{2}\right)$ and subtends a large angle at the sample (about $14^{\circ}$ ); the PIXE detector is somewhat smaller $\left(80 \mathrm{~mm}^{2}\right)$, but is moveable and subtends about $25^{\circ}$ when fully 
inserted. However, the effective takeoff angle from the sample (which for these large detectors is not the same as the average takeoff angle) is assessed experimentally. We do not do the large angle

correction: in principle the reaction cross-sections should be integrated over all takeoff angles to obtain the correct effective cross-section, but we simply take an average that fits the dataset. The inverse situation (where the irradiation area is not small) has been treated for PIXE/XRF (for the APXS instrument of the Mars Rover) by Campbell et al., $2019^{46}$.

\section{Scattering Cross-Sections}

In the absence of evidence to the contrary, theoretical screened ${ }^{47}$ RBS cross-sections were used in this work for $\mathrm{Pb}, \mathrm{Ba}, \mathrm{As}, \mathrm{Mn}$. Evaluated $\mathrm{EBS}$ scattering cross-sections are used where they are available: these fit all available experimental data to a nuclear model. The $\operatorname{SigmaCalc}^{48}$ (v.2.0 $\left.0^{49}\right)$ code is publicly available, and can generate cross-section functions for any given scattering angle. Some of the important reactions have been published separately: these include the $\mathrm{C}^{50,51}, \mathrm{O}^{52}, \mathrm{Mg}^{53}$, $\mathrm{Al}^{54}$, and $\mathrm{Si}^{55}$ reactions (for proton scattering, see Table 2); and the $\mathrm{C}^{56}, \mathrm{O}$ [ref.22], and $\mathrm{Si}^{57}$ reactions (for alpha scattering). Where evaluated data are not available, measured data are taken from the collection in $I B A N D L^{58,59}$. Of course, $3 \mathrm{MeV}$ proton scattering on $\mathrm{He}, \mathrm{Li}, \mathrm{Na}, \mathrm{Mg}, \mathrm{K}, \mathrm{Ca}, \mathrm{Fe}$ are all also strongly non-Rutherford, and appropriate cross-sections are used (see Table 2).

RBS is known to be a poor approximation for $\mathrm{Fe}$ (which has some two dozen strong and sharp resonances for this energy, see SigmaCalc and Lindstrom et al, $1971^{60}$ ) and hence presumably Mn as well (there are measured nuclear reactions at $2 \mathrm{MeV}$, see IBANDL and Kenny et al, 1980 ${ }^{61}$ ). EBS cross-sections are used for Fe but not Mn, since the Fe signal is noticeable in EBS but the Mn signal is not (in any case there are no EBS data in $I B A N D L$ for $\mathrm{Mn}$ ).

There are also no EBS cross-section data in IBANDL for $\mathrm{As}, \mathrm{Ba}$ or $\mathrm{Pb}$, but $\mathrm{Zn}$ has an EBS resonance just below $3 \mathrm{MeV}$ (Bogdanović et al, 1995 $5^{62}$ ) and both isotopes of Ag have substantial gamma yields below $2.5 \mathrm{MeV}$ and measurable yields down to $1.5 \mathrm{MeV}$ and below (Deconninck \& Demortier, $1975^{63}$ ). The same authors also measured substantial gamma yields for Au at $2.5 \mathrm{MeV}$. At present the RBS/EBS boundary for a proton beam is poorly defined for $Z>26$ (see Fig.9 of the 2016 Review [ref.1]). Nevertheless, we assume RBS for the heavier elements (Mn, As, $\mathrm{Sr}, \mathrm{Ba}, \mathrm{Pb}$ ), that is, we assume that Rutherford cross-sections are good approximations.

\section{Precision/Accuracy}

This work is concerned with a careful determination of uncertainty associated with Total-IBA: for convenience, considering the confusion surrounding terms relating to uncertainty, we will give definitions of "uncertainty" and related terms following the VIM". Correct methods of treating "uncertainty" is explained authoritatively by the GUM ${ }^{65}$.

It is essential to start by noting that the VIM (\$2.9) insists that to be a valid measurement, its uncertainty must also be reasonably estimated; expanding on this by saying that an "Uncertainty Budget" (\$2.33) is a "statement of: a measurement uncertainty, of the components of that measurement uncertainty, and of their calculation and combination" which "should include the measurement model, and the measurement uncertainties associated with the quantities in the measurement model, covariances, type of applied probability density functions, degrees of freedom, type of evaluation of measurement uncertainty, and any coverage factor". The underlined expressions are relevant here and are discussed in detail by both the VIM and the GUM. They are very general statements applicable to all types of measurement: our case is very simple numerically so that (for example) we will not need to consider "covariances" explicitly, and we will always be able to express standard uncertainties simply as the standard deviation of the expected distribution of measurements. 
We also note here that the GUM and the VIM explicitly avoid any consideration of the "true value of a measurement" on the grounds that this is unknowable in principle. The use of "error" (instead of "uncertainty") is also deprecated (except for convenience in "error bars"), unless a mistake is to be indicated.

The accuracy of a measurement is defined by the VIM (\$2.13) as the "closeness of agreement between a measured quantity value and a true quantity value of a measurand", commenting that it is "NoтE 3: sometimes understood as closeness of agreement between measured quantity values that are being attributed to the measurand"; although insisting that, strictly speaking, "accuracy" is a qualitative judgment, not a quantitative measure: "NoтE 1: The concept 'measurement accuracy' is not a quantity and is not given a numerical quantity value".

Here we treat the accuracy of a measurement as being given by the standard combined uncertainty (VIM \$2.31) of the measurement as evaluated by the uncertainty budget (that is, considering all known sources of uncertainty). The proper use of the Uncertainty Budget in IBA was powerfully argued for nearly a generation ago by the (then) IRMM group at Geel. ${ }^{66}$ In the case of the EPMA measurements, their accuracy is assessed from their reproducibility (VIM \$2.25). Strictly, the VIM regards this measure as a sort of precision, but an evaluation of the reliability of the EPMA measurements gives us confidence that in this case it is a reasonable proxy for accuracy.

The precision of a measurement is defined by the VIM $(\$ 2.15)$ as the "closeness of agreement between indications or measured quantity values obtained by replicate measurements on the same or similar objects under specified conditions". It is essentially a measure of the repeatability (VIM \$2.20) of the measurements, that is, not considering some possible sources of uncertainty. Note that the accuracy cannot be better (smaller) than the precision, but usually the precision is smaller than the accuracy (unless counting statistics dominate the uncertainty, in which case the precision is essentially the same as the accuracy). The term "standard uncertainty" usually refers to the precision, that is, the standard deviation of the observed distribution of measurements in a particular case.

Uncertainties may be expressed as absolute or relative: for example in Table 4 the $\mathrm{Na}_{2} \mathrm{O}$ content of the glass is given as $12.43 \pm 0.21 \mathrm{wt} \%$ (absolute) or $12.43 \mathrm{wt} \% \pm 1.7 \%$ (relative).

The GUM says (\$6.1.2) "Although [the standard combined uncertainty] can be universally used to express the uncertainty of a measurement result, in some ... applications ... it is often necessary to give a measure of uncertainty that defines an interval about the measurement result that may be expected to encompass a large fraction of the distribution of values that could reasonably be attributed to the measurand." Hence the idea of "expanded uncertainty" (GUM \$6.2), where the "coverage factor $k$ " (GUM \$6.3) specifies the level of confidence in the specified uncertainty. In our simple cases, where the distribution of measurements is expected to be essentially normal, we are used to specifying a 95\% confidence interval as " 2 sigma" and a $99 \%$ confidence interval as "3 sigma". In the more general terminology of the GUM these would be expressed as " $k=2$ " or " $k=3$ ". In GUM terms, " $k=1$ " would refer simply to the standard uncertainty. But $k$ is used only in the context of an expanded uncertainty.

\section{Sodium Migration during Analysis}

In the wider study for which this study is preliminary, glass weathering effects such as alkali metal leaching are expected to be prominent, and will affect the Na profile near the surface. Therefore, to measure such profiles it is necessary to establish the analytical validity of $\mathrm{Na}$ measurements for these samples, since it is well known that $\mathrm{Na}$ is mobile under a charged particle beam. Although IBA is not deliberately destructive, of course energetic beams can damage or modify samples in various ways, ${ }^{67}$ of which this is only one. 
Walker \& Howitt ${ }^{68}$ find that Na-depletion is a function of electron current but not of electron energy (they used 10,15, $20 \mathrm{keV}$ on the SEM), observing Na depletion to $70 \%$ of the initial value after $\{100$, $150,250,500\}$ secs for electron current densities of $\{4.8,1.2,0.7,0.3\} \mathrm{mA} / \mathrm{cm}^{2}$.

For the present work the Na content in the glass is determined by EPMA since there is effectively no signal for Na in PIXE (although in the wider study Na will be measured by H-PIXE, He-PIXE and PIGE).

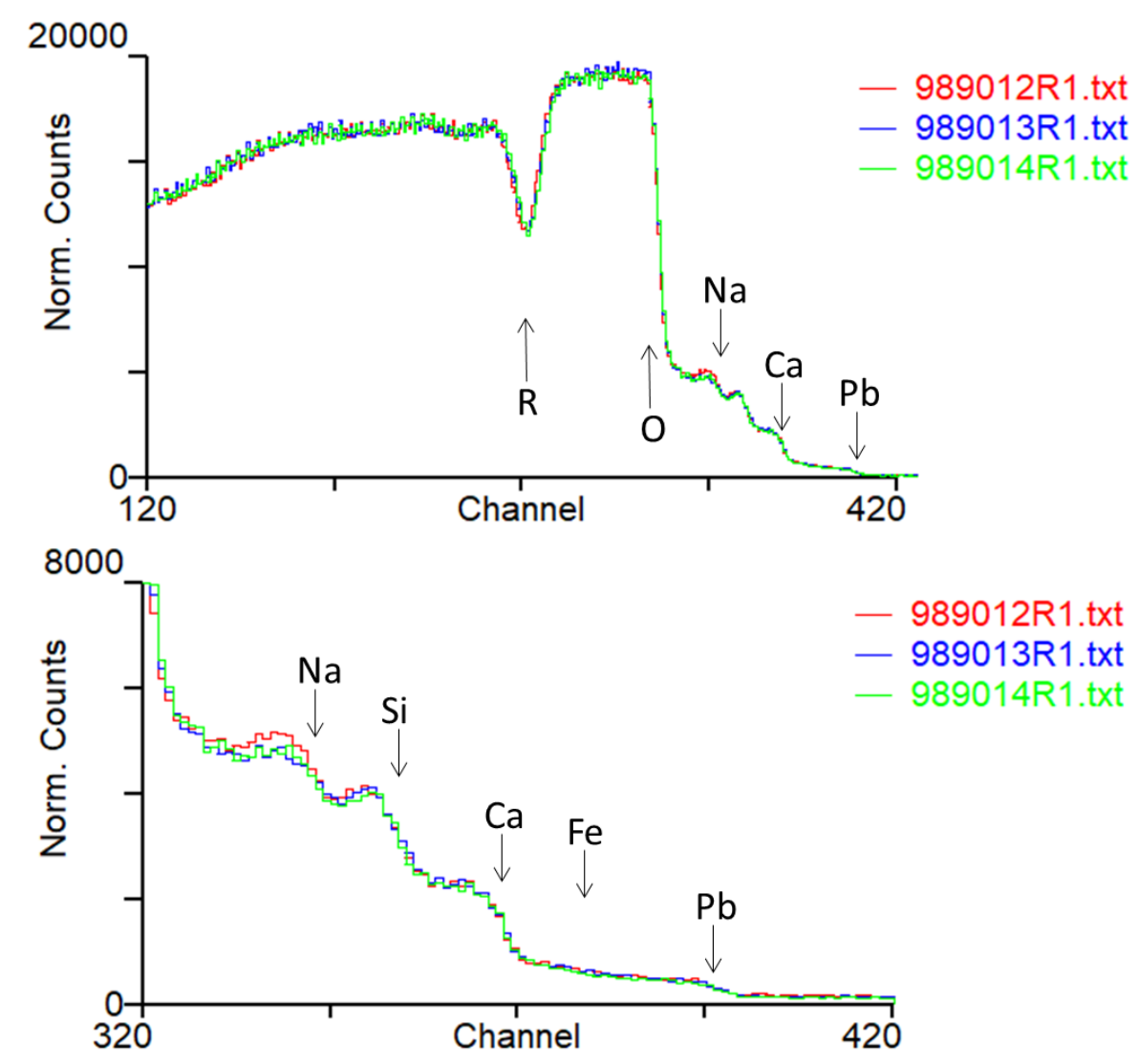

Figure 1: Normalised EBS spectra of Rosslyn glass with increasing current density

OMDAQ run numbers $989012,13,14.2827 \mathrm{keV}$. The $2663 \mathrm{keV}$ resonance in the O signal is marked "R". Elemental edges are marked Above: full spectrum; Below: detail. The signal above the $\mathrm{Pb}$ edge is pileup.

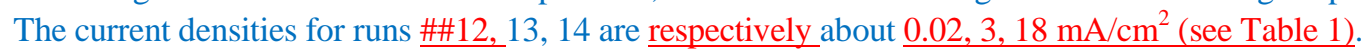

We have confirmed Walker \& Howitt's result using beams of energies $\{10,20,30 \mathrm{keV}\}$, beam current densities ranging from $0.3 \mathrm{~mA} / \mathrm{cm}^{2}$ to over $300 \mathrm{~mA} / \mathrm{cm}^{2}$, and spot sizes from focussed $(2 \mu \mathrm{m})$ to $100 \mu \mathrm{m}$. $\mathrm{Na}$ instability in this glass under a $20 \mathrm{keV}$ electron beam was measured by us over 60 secs at beam current densities $2 \mathrm{~mA} / \mathrm{cm}^{2}$ ( $40 \mathrm{nA}$ with $50 \mu \mathrm{m}$ beam diameter). The present results were obtained with lower current densities of $0.25 \mathrm{~mA} / \mathrm{cm}^{2}$ ( $20 \mathrm{nA}$ with defocussed beam $100 \mu \mathrm{m}$ diameter), for which stability to the electron beam is obtained over time scales long enough to make valid measurements.

However, electrons and ions are not the same: Battaglin et al. ${ }^{69}$ investigated Na mobility during $\mathrm{Ar}^{+}$ implantation and found that Na-depletion was simply a function of the energy deposited in the volume. But the nuclear energy loss behaviour of heavy ions is entirely different from that of protons: the effect of $600 \mathrm{keV}$ proton irradiation was also explored in a separate broad-beam study by Battaglin et al. ${ }^{70}$ who found a "residence time" effect, although at $140 \mu \mathrm{A} / \mathrm{cm}^{2}$ the residence time (see their Fig.2) is near zero. But they also say that the residence time effect depends on beam current more than the current density, citing measurements with a spot size a factor 2 smaller; they use a uniformly 
irradiated $4 \mathrm{~mm}^{2}$ area (this is apparently for both spot sizes). Ours is a focussed proton beam orders of magnitude smaller (with an average current density an order of magnitude smaller), so that we may expect the residence times to become significant.

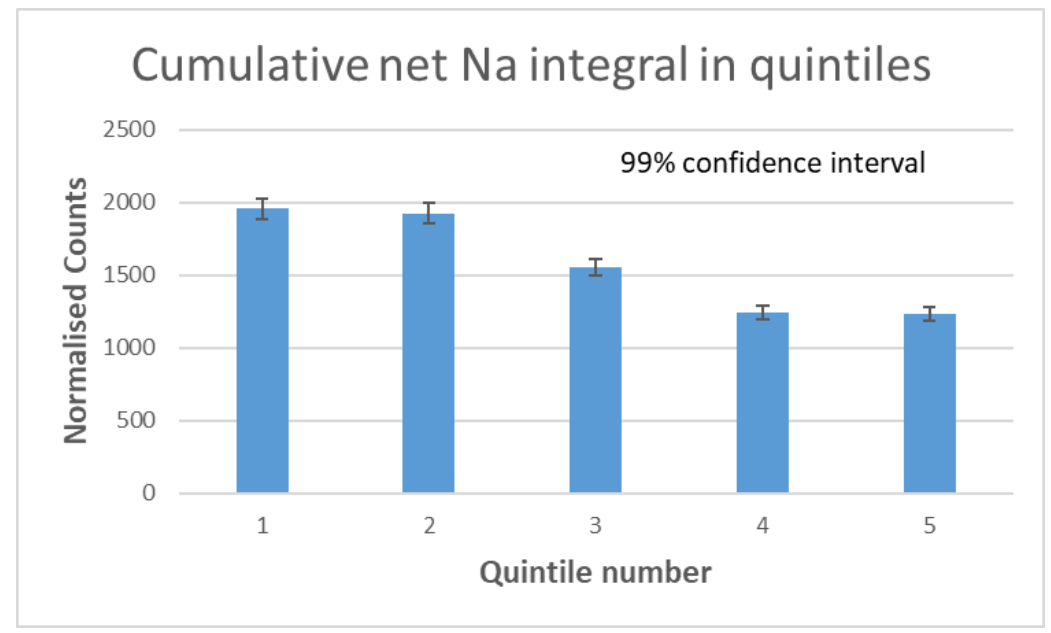

Figure 2: Na mobility in Rosslyn Glass under a proton beam

Background corrected normalised counts from \#989013 are shown, with error bars from counting statistics

On the other hand, March \& Rauch ${ }^{71}$ investigate Na depletion in leached soda-lime glasses using the $591 \mathrm{keV}$ resonance of the ${ }^{23} \mathrm{Na}(\mathrm{p}, \alpha)^{20} \mathrm{Ne}$ reaction (see Carnera et al, $1977^{72}$ : note that Battaglin et al. use the same NRA reaction; Carnera et al.'s cross-section data are not included in IBANDL) with a proton beam of 7-10 nA scanned over $3 \times 3 \mathrm{~mm}^{2}$ and a total dose of about $5.10^{13}$ protons (about $10 \mu \mathrm{C}$, or about 15 minutes irradiation). They believe that Na mobility under these conditions "should be small".

This conclusion is supported by measurements of Mosbah \& Duraud ${ }^{73}$, who investigate two synthetic glasses (one of which is similar both to ours and also to the "Brill-B" glass reported by Vicenzi et al. ${ }^{74}$ ) using a $2 \mathrm{MeV}$ proton beam with high fluxes from 2 to $23 \mathrm{~mA} / \mathrm{cm}^{2}$ to damage the glasses. Our fluxes are orders of magnitude smaller (see Fig.1). This Brill-B glass has been used as a standard for "decades" (T.Calligaro, private communication) without seeing any Na loss.

Finally, we mention in passing Melcher et al. (2010) ${ }^{75}$ for a recent account of glass weathering as revealed by SIMS, AFM and SEM; although it does not directly address the problem of Na mobility under an analytical beam they clearly believe that they have made valid measurements.

Figure 1 shows that Na mobility effects can be observed in EBS measurements of this glass. There is a noticeable $\mathrm{Na}$ depletion for measurements at high flux density. For enhanced sensitivity, these EBS measurements are made at an energy where the (non-Rutherford) scattering cross-section ratio for $\mathrm{Na} / \mathrm{Si}$ is near a maximum. However, the thickness of the modified layer cannot be determined from these data, except to say that it must be more than about $1 / 2 \mu \mathrm{m}$.

Figure 2 shows quintiles from the list mode file \#989013, which was collected over 30 minutes with a high beam current of about $300 \mathrm{pA} / \mu \mathrm{m}^{2}$; that is, segments integrated over 6 minutes. It is very clear that there is systematic variation between the start and end of data collection: not only does the $\mathrm{Na}$ signal decrease significantly but the Si signal also increases slightly (as it must due to mass closure). In confirmation of this, the variation of the integrals is much more than expected simply from counting statistics for the Na signal, and also slightly more than expected for the Si signal.

Figure 2 also shows that there appears to be a ten minute "incubation time" before the Na becomes mobile, even at the high average beam current used for \#989013 (which is some 200 times greater than for \#989012). The fact that the first two quintiles of the \#989013 spectrum are indistinguishable 
either from each other or from the \#989012 spectrum is evidence that Na migration is not a process that starts very rapidly, unlike $\mathrm{H}$ loss for example.

We conclude that we can measure reliably (that is, without Na migration) for a suitably low flux proton beam. In any case this present work is not sensitive to the Na content, which we do not here try to measure by IBA.

\section{Calibration}

The calibration of the EPMA is automated under proprietary software, and details are not normally available to the analyst. But the calibration is absolute per line, so that a recursive analysis first obtains the interaction volume from the thick target composition deduced from assuming mass closure and full oxidation; and then effectively gives the measured elements as an areal density converted to a mass fraction per measured element from the interaction volume, without normalising the results to $100 \%$ mass closure. Therefore the analysis is valid provided that mass closure is approximately obtained. It is worth noting that XRF (but not EPMA or PIXE) can determine the average $\mathrm{Z}$ of the material from the primary photon scattering signals, allowing the hydration state of the sample also to be inferred. ${ }^{76}$ This is Discussed below.

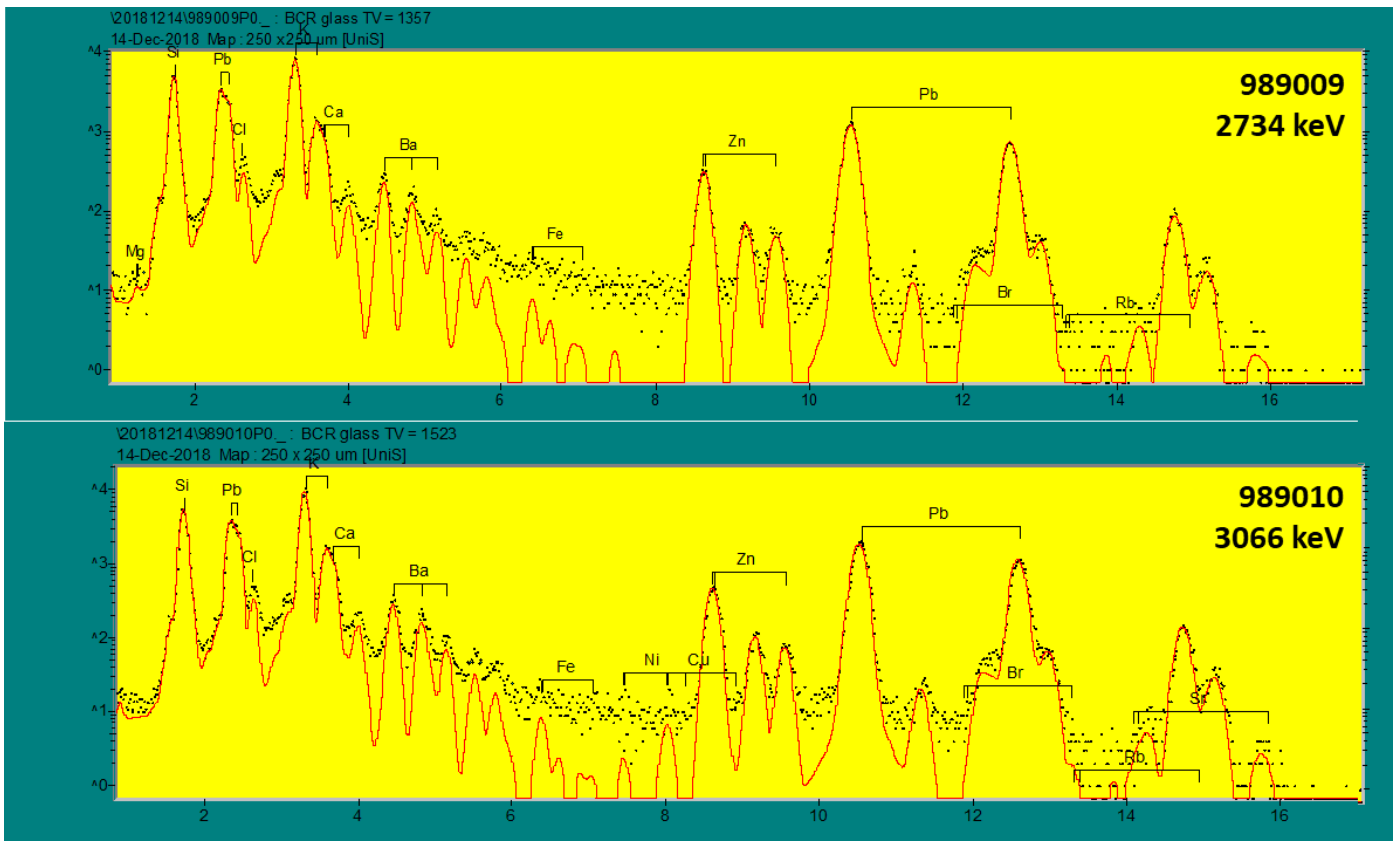

Figure 3a: PIXE spectra from BCR glass with GUPIX fits

The ordinate has a logarithmic scale ranging from $10^{0}-10^{4}$. The GUPIX fit does not include the background

IBA experimental parameters were determined using the BCR126A [ref.21] certified standard (a lead glass with elemental content about 60 at $\%$ O, 26 at $\% \mathrm{Si}, 6$ at $\% \mathrm{~K}, 3$ at $\% \mathrm{~Pb} \& \mathrm{Na}$ and 0.9 at $\% \mathrm{Li}$ ); these fitted parameters include sample tilt and the effective detector solid angles, the filter thickness and efficiency curve for the PIXE detector, and the accelerator energy and EBS spectrometer calibrations. This method of energy calibration using nuclear resonances in EBS [ref.22] is sensitive to small sample-charging effects: much larger effects can exist (without electrostatic instability) which are observable directly with RBS. ${ }^{77}$ The angles of the detectors to the beam are determined separately, but confirmed by this calibration.

Figure 3a shows the PIXE data with the GUPIX fit, where GUPIX is used as a convenient way of identifying characteristic lines as well as obtaining valid line areas even where there are line overlaps (it also fits pileup and escape peaks). The $\mathrm{Cl}$ signal is assumed to be from surface contamination and is 
ignored in the NDF simulation. GUPIX allows the detector response function to be individually fitted per detector, ${ }^{78}$ but here it is defaulted (which has only a marginal effect on the extracted line areas).

Figure 3b shows the EBS data with the NDF fit. From the $\mathrm{Pb}$ and $\mathrm{O}$ edges of these spectra the spectrometer gain may be obtained, and the incident beam energy (and hence the GVM factor) is obtained from the position of the $2663 \mathrm{keV}$ resonance in the $\mathrm{O}$ signal, which for the $3066 \mathrm{keV}$ measurement is very sensitive to pathlength thus giving a sample tilt of $5^{\circ}$ away from the particle detector.

Note that the parameters are fitted but the spectrum is simulated from the certified glass composition, using appropriate scattering cross-section functions as given in Table 2. The mismatch in the EBS spectrum for the Si signal due to the underestimated Si scattering cross-section (discussed below) is less noticeable for this EBS spectrum because of the high background of the $\mathrm{Pb}$ signal. The charge-solid-angle product for the particle detector is given by the total yield of the spectra. The gain is assumed linear (that is, ignoring the particle detector pulse height defect, ${ }^{79}$ since spectra collected with proton beams of similar energies have negligible non-linear effects).
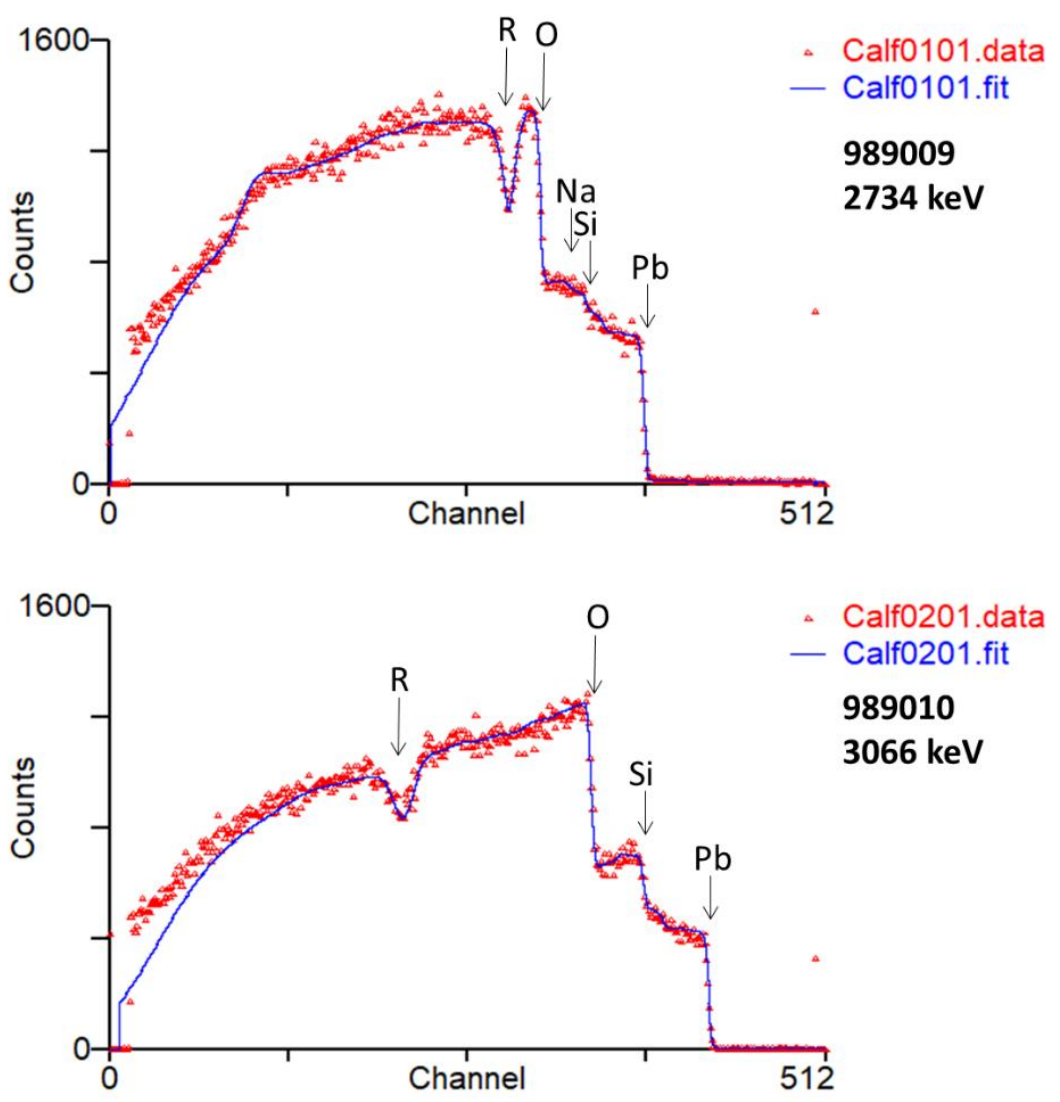

Figure 3b: EBS spectra from BCR glass with NDF simulations 


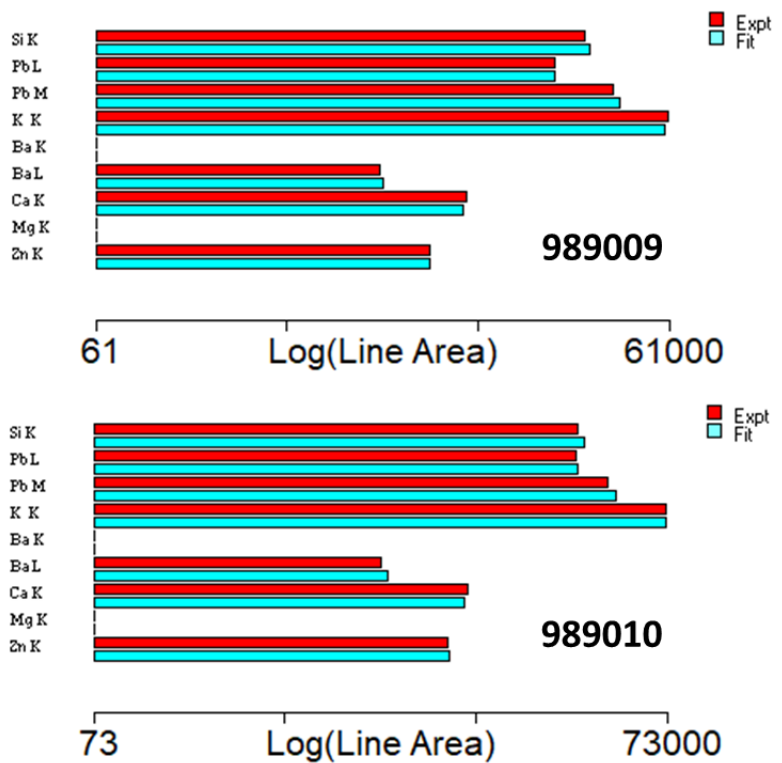

Figure 3c: PIXE data and NDF simulation of BCR glass

charge-solid-angle product from $\mathrm{Pb} \mathrm{L}$ line and detector filter thickness (151 $\mu \mathrm{m} \mathrm{Be})$ from $\mathrm{Si} \mathrm{K}$ line. Sample tilted $5^{\circ}$ towards X-ray detector. Numerical data in Table 3.

\begin{tabular}{|l|rrc|rcc|c|}
\hline \multirow{2}{*}{ Line } & \multicolumn{3}{|c|}{ \#909009: 2734 keV } & \multicolumn{3}{|c|}{ \#909010: 3066 keV } & \multirow{2}{*}{ Hfactor } \\
\cline { 2 - 7 } & Data & Sim & data/sim & Data & Sim & data/sim & \\
\hline Si K & 22015 & 23392.1 & 0.94 & 25113 & 27134.1 & 0.93 & 0.9 \\
Pb L & 15445 & 15513.2 & 1.00 & 24411 & 24890.4 & 0.98 & 1.0 \\
Pb M & 31099 & 33616.8 & 0.93 & 35585 & 40021.5 & 0.89 & 1.2 \\
K K & 60455 & 58651.7 & 1.03 & 71844 & 72996.3 & 0.98 & 1.2 \\
Ba L & 1878 & 1945.6 & 0.97 & 2355 & 2568.9 & 0.92 & 1.0 \\
Ca K & 5356 & 5089.8 & 1.05 & 6630 & 6421.5 & 1.03 & 1.2 \\
Zn K & 3414 & 3454.1 & 0.99 & 5218 & 5384.5 & 0.97 & 1.2 \\
\hline
\end{tabular}

Table 3: PIXE yield (counts per line) for BCR glass

These data shown are graphically in Figure 3c. Line areas simulated by NDF from certified glass composition. Sample tilted $5^{\circ}$ towards X-ray detector: gives correct results for $\mathrm{Ca}$ and $\mathrm{K}$ lines.

Table 3 shows the numerical values obtained (using the given "H-factor"). Here the high energy major line $(\mathrm{Pb} \mathrm{L} \alpha)$ determines the charge-solid-angle product; the low energy major line ( $\mathrm{Si} \mathrm{K}$ ) largely determines the effective detector filter thickness of $151 \mu \mathrm{m} \mathrm{Be}$ (which includes the nominal $12.5 \mu \mathrm{m}$ Duraberyllium detector window), which is about $10 \mu \mathrm{m}$ (of Be equivalent) thicker than expected probably mostly due to icing. The "H factor" simply multiplies the simulated line counts by the given value.

Given this calibration, Figure 3c shows the NDF simulation of the PIXE line areas for the BCR glass standard. Note that this $\mathrm{H}$-factor calibration for PIXE only has a precision of $10 \%$ deriving as it does from a single calibration sample.

The calibration curve (labelled "H-factor" in Table 3) is well-behaved, being uniformly 1.2 for the K (and M) lines (but reduced to 0.9 for the lowest energy), and 1.0 for the L lines. Notice that the change of energy between $\# 989009$ and $\# 989010$ has a noticeable effect on the spectra, which are simulated faithfully (usually better than $2 \%$ ). $\mathrm{K}$ and $\mathrm{Ca}$ are sensitive to pathlength to the detector, and the $5^{\circ}$ tilt inferred from the EBS spectrum is confirmed independently by the PIXE spectra. 


\section{Analytical Protocol}

Having used the certified standard (the BCR126A lead-glass sample) to calibrate the spectrometry system, we use the calibrated system to measure the unknown sample (see Figures 4, 5). Note that the beam is assumed normal to this sample: the tilt angle depends on the sample mounting and is not necessarily the same as for the calibration sample.

In the general case of an inhomogeneous sample, the PIXE data can only be interpreted using the depth profile obtained from the EBS spectra. Even though in this present simpler case the sample is homogeneous with depth, we still use a general method; partly (i) because in the simple case important aspects of the accuracy of the general case become tractable and can be evaluated in detail, partly (ii) because the PIXE (Figure 4) here has no sensitivity to Na (a matrix element: it also has an unreliable signal for $\mathrm{Al}$, a minor element undetectable in EBS), and partly (iii) because it is easy to implement chemical priors in DataFurnace.

The EBS spectrum (Figure 5a) is analysed as a glass, with the constituents grouped to match the major information in the spectrum, and treated as oxides: that is, applying prior chemical constraints to the data (see the examples and discussion in Jeynes et al, 2000 [ref.45], and $\$ 8.3$ of the 2003 Topical Review $^{80}$ ). In Figure 5a there are four steps in the spectrum: at the $\mathrm{O}, \mathrm{Si}, \mathrm{Ca}$ and $\mathrm{Pb}$ edges. Therefore three "logical elements" (LE, see Barradas \& Jeynes, 2008 [ref.17]) are used, where "?" indicates that the LE composition may vary during the fit, and where in all cases the (unnormalised) molar composition is indicated:

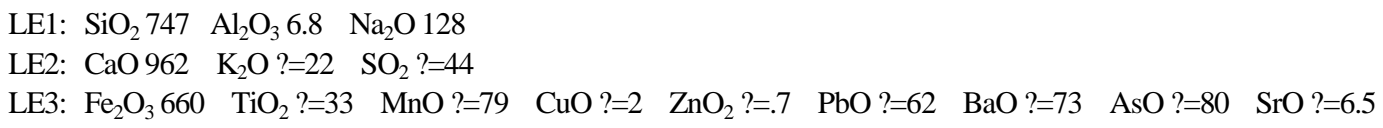

In this case the $\mathrm{Si}$ Al:Na ratios are obtained from EPMA: this is another prior chemical constraint for the IBA. The $\mathrm{Al}$ is undetectable in the EBS spectrum being far below the detection limit: it is also unmeasurable in the PIXE since the Al signal background is both high and not well-modelled. The Na is measurable in EBS but the sensitivity is relatively poor because of the high background signal. There is no signal in this case for Na in the PIXE data. Had EPMA not been available to determine the Si:Al:Na ratios we would have used EBS, in which case LE1 would have been split into two logical elements (ignoring the $\mathrm{Al}$ ): $\mathrm{SiO}_{2}$ and $\mathrm{Na}_{2} \mathrm{O}$. The uncertainties would then also have increased.

LE1 is a fixed mixture of the oxides of $\mathrm{Si}, \mathrm{Al}, \mathrm{Na}$ (using the prior information from EPMA), but LE2 is a variable mixture of the oxides of $\mathrm{Ca}, \mathrm{K}, \mathrm{S}$, and LE3 is a (variable) mixture of 9 oxides. The DataFurnace code fits the spectrum first by obtaining "best" ratios of logical elements 1,2,3 (given their starting composition), then adjusts the composition of the variable LEs, and then iterates. The fitting can be either a local minimisation (using a standard grid search) or a global minimisation (using simulated annealing: see Barradas et al, 1997 [ref.27]). The objective function being minimised is in this case a pseudo- $\chi^{2}$ function obtained from both the EBS spectrum and the PIXE line areas.

It is very easy and quick using the DataFurnace simulator to obtain approximate values for the ratios of all the logical elements, since it simultaneously calculates both the EBS spectrum and the PIXE line areas, with both displayed together. But obtaining a high quality fit is nearly impossible with manual methods because all the four main EBS signals are quite strong functions of all the others.

In this case the PIXE determines the compositions of the two variable LEs almost independently of the EBS, but the Si:Ca ratio is well-determined both by EBS and by PIXE (EBS and PIXE are here independent measurements which will agree only if the calibrations are correct). In this case, where the sample is homogeneous with depth, the PIXE is independent of the EBS (otherwise it would not be). The EBS always gives information about the surface composition nearly independent of PIXE 
since the step height is well defined (although the interpretation of the step background may depend quite strongly on the PIXE, as here).

In any case, the step height for the EBS O signal is always given by the cation content, that is, this signal in the EBS spectrum is not independently determined even though it is the dominant signal. This is one major difference between RBS and EBS: in RBS the $\mathrm{O}$ signal is usually very small (because the RBS cross-section goes with $\mathrm{Z}^{2}$ ), even where the $\mathrm{O}$ content dominates. But for EBS the backscattering cross-section for $\mathrm{O}$ is greatly enhanced (by a factor $\sim 8$, see Table 8a below) so that the $\mathrm{O}$ signal is large even for a lead-glass (see Figure 3b). This means that where samples have no elements lighter than O, the EBS spectra give 100\% mass closure: for such samples this is a powerful extra constraint on the solution.

It is essential to recognise that, given the charge-solid-angle product (a well defined experimental value for the spectrum) and the scattering cross-section functions (well defined constants of nature), the number of counts in the EBS spectrum is a strong function of the average atomic number $(\mathrm{Z})$ of the sample (well-determined where the sample is homogeneous). Note that the scattered photon signal in XRF is also a function of $\mathrm{Z}$ ([ref.7 $\underline{6}])$.

\section{Results}

Table 4 shows the results of the EPMA analysis, where the (average) wt $\%$ results in the Table have a mass closure of $98.0 \pm 0.6 \%$ (hence the "Missing" component of $2 \mathrm{wt} \%$ ), and where the given uncertainties are the relative standard deviations of the 10 repeat measurements (of course the software assumes standard glass oxidation). Note that the "Missing" uncertainty is dominated by the uncertainty of the main lattice-former element ( $\mathrm{Si})$.

The missing elements are supplied by the PIXE analysis (see below) from which we obtain the average atomic weight (43.35 amu) of the component missing in EPMA and hence the mol\% column in Table 4. The mol\% uncertainty is derived from the measured wt $\%$ uncertainty. The present PIXE analysis is insensitive to $\mathrm{Na}$ and $\mathrm{Al}$, so we fit the IBA data using $\mathrm{Na} / \mathrm{Si}$ and $\mathrm{Al} / \mathrm{Si}$ ratios derived from EPMA. Table 4 also gives calibration data for the six lines measured.

\begin{tabular}{|l|rrrc|lrr|}
\hline \multicolumn{7}{|c|}{ Rosslyn glass sample } & \multicolumn{3}{c|}{ Calibration from standards } \\
\hline Line & \multicolumn{1}{|c|}{ wt\% } & $\mathbf{\pm}$ & $\mathbf{m o l} \%$ & $\mathbf{\pm}$ & Line & nA & cps \\
\hline Na2O & 12.43 & $1.7 \%$ & 12.79 & $1.7 \%$ & Na & 20.0 & 3518 \\
SiO2 & 70.38 & $0.4 \%$ & 74.70 & $0.5 \%$ & Si & 20.0 & 35178 \\
K2O & 0.32 & $2.6 \%$ & 0.22 & $1.7 \%$ & K & 20.0 & 12364 \\
CaO & 12.69 & $0.7 \%$ & 9.62 & $0.5 \%$ & Ca & 20.0 & 40721 \\
Al2O3 & 0.66 & $1.4 \%$ & 0.68 & $1.5 \%$ & Al & 10.0 & 37476 \\
Fe2O3 & 1.50 & $0.6 \%$ & 1.00 & $0.4 \%$ & Fe & 20.0 & 42179 \\
\hline Missing & 2.03 & $0.6 \%$ & 1.00 & $0.3 \%$ & & & \\
\hline sum & 100.00 & & 100.00 & & & & \\
\hline
\end{tabular}

Table 4: EPMA analysis of Rosslyn glass

Relative standard uncertainties are given, except for the "Missing" column where absolute standard uncertainties are given

Figure 4 shows a PIXE spectrum (OMDAQ \#989020) from the Rosslyn glass cross-section sample measured by EPMA. Of course, far more elements are visible in PIXE than were measured by EPMA. But there is no PIXE signal for $\mathrm{Na}$, and the signal for $\mathrm{Al}$ is unreliable in the presence of the poorly fitted low energy tailing. Therefore we impose the Na:Si and Al:Si ratios from EPMA in the Total-IBA fitting, and otherwise use the PIXE calibration from the BCR lead-glass standard sample. The results for this are shown numerically in Table 5. There is an EBS signal for Na, but its 
sensitivity is limited (see Table 7a below). However, the EPMA is relatively sensitive, as well as having good accuracy since the EPMA instrumental factor is directly calibrated for $\mathrm{Na}$.

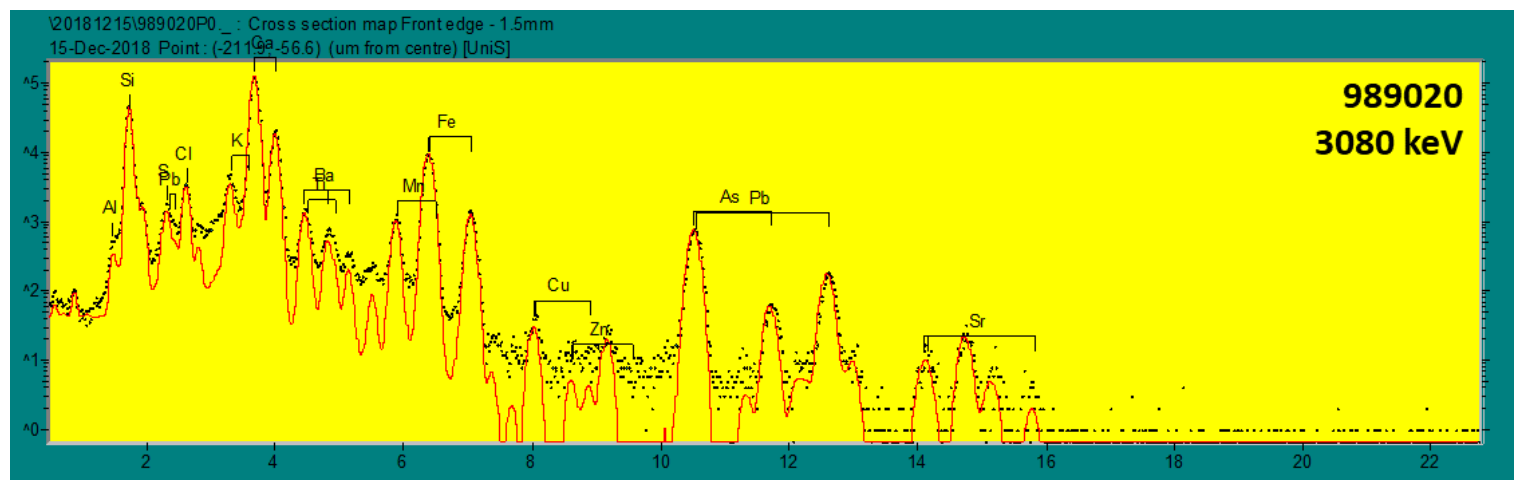

Figure 4: PIXE of Rosslyn glass with GUPIX fit

Centre of cross-section, $500 \times 500 \mu \mathrm{m}^{2}$ map, $2 \mathrm{hr}$ run time

\begin{tabular}{|l|ccccccc|c|}
\hline & SiO2 & Al2O3 & Na2O & CaO & K2O & SO2 & Fe2O3 & Totals \\
\hline IBA & $76.3 \%$ & $0.69 \%$ & $13.1 \%$ & $8.20 \%$ & $0.179 \%$ & $0.318 \%$ & $0.80 \%$ & $\mathbf{9 9 . 3 \%}$ \\
$\mathbf{\pm}$ & $1.4 \%$ & & & $0.43 \%$ & $0.010 \%$ & $0.023 \%$ & $0.05 \%$ & \\
\cline { 1 - 2 } & $74.7 \%$ & $0.68 \%$ & $12.8 \%$ & $9.62 \%$ & $0.216 \%$ & & $1.001 \%$ & $\mathbf{9 9 . 0 \%}$ \\
$\mathbf{\pm}$ & $0.4 \%$ & $0.02 \%$ & $0.3 \%$ & $0.05 \%$ & $0.004 \%$ & & $0.004 \%$ & \\
$\mathbf{\Delta}$ & $\mathbf{2} \%$ & & & $-15 \%$ & $-17 \%$ & & $-20 \%$ & \\
\hline & TiO2 & MnO2 & CuO & ZnO2 & PbO & BaO & AsO & SrO \\
\hline IBA & $0.0455 \%$ & $0.0998 \%$ & $0.0025 \%$ & $0.0007 \%$ & $0.0656 \%$ & $0.1003 \%$ & $0.0842 \%$ & $0.0068 \%$ \\
$\mathbf{\pm}$ & $0.0040 \%$ & $0.0061 \%$ & $0.0003 \%$ & $0.0003 \%$ & $0.0045 \%$ & $0.0062 \%$ & $0.0055 \%$ & $0.0010 \%$ \\
\hline
\end{tabular}

Table 5: Composition (mol\%) of Rosslyn glass cross-section by IBA and EPMA

EPMA results from Table 4 are included. The " \pm " rows give the combined absolute standard uncertainties from counting statistics (Total-IBA) and reproducibility (EPMA) The " $\Delta$ " row gives the relative difference between IBA and EPMA. "Totals" exclude $\mathrm{SO}_{2}$ and trace elements Note that the ratio of $\mathrm{Ca}, \mathrm{K}$ and $\mathrm{Fe}$ to $\mathrm{Si}$ is obtained by Total-IBA independent of EPMA.

Table 5 shows the final IBA result with EPMA for comparison. That the $\mathrm{Ca}$ and $\mathrm{K}$ are lower than expected may indicate a sample tilt, but this spectrum is less sensitive than the lead-glass spectra to tilt effects since there is far less $\mathrm{Pb}$ and hence far less absorption by the $\mathrm{Pb} \mathrm{M}$ line. That the $\mathrm{Fe}$ content is low compared to EPMA is a consequence of the high uncertainty of the (effectively) uncalibrated PIXE signal.

The "Totals" inset shows the mol\% sum of the six elements measured by EPMA: note that the IBA and EPMA are indistinguishable given the EPMA uncertainty (see Table 4). Note also that this consistency is not a consequence of the analysis since the $\mathrm{Si}: \mathrm{Ca}: \mathrm{Pb}$ ratios are determined by EBS independently of EPMA results.

Table 6 summarises the final measured elemental glass composition in both mol\% and wt $\%$ for convenience.

The PIXE in Figures 4, 5b shows expected (calculated) but unobserved signals for Ba K (32 keV) and $\mathrm{Sr} \mathrm{L}(1.8 \mathrm{keV})$. There is no sensitivity for either since the $\mathrm{Ba} \mathrm{K}$ is above the measured energy range and the $\mathrm{Sr} \mathrm{L}$ is overlapped by the strong Si signal (it is between the $\mathrm{Si} \mathrm{K} \alpha$ and $\mathrm{K} \beta$ peaks). The GUPIX fitting also grossly overestimates the $\mathrm{Al}$ signal, due to the very poor fitting of the low energy detector tailing effects. This signal is adjusted to fit the calculation. 
Figure 5a gives more detail of the fitting of the EBS spectrum showing all the minor elements contributing to the signal.

\section{Benchmarking EBS scattering cross-sections}

Following the work of Paneta et al $^{81}$ (stimulated by an IAEA Coordinated Research Project which reported formally in 2015 [ref.58], but see also Abriola et al., 2011 [ref.59]), evaluated EBS scattering cross-sections have systematically been compared against benchmarking data (Gurbich, 2016 [ref.49]) and the central importance of benchmarking underlined. The issue is how to assess the uncertainty of an EBS cross-section function. This was previously (2013) addressed directly by Gai $\&$ Gurbich $^{82}$ who used the standard method of deriving the covariance matrix: however, they also showed that there existed quite large systematic errors that are unquantifiable in detail, commenting that in such cases these standard statistical methods are not strictly valid. They also commented that Mayer's earlier $\left(2012^{83}\right)$ approach to assessing EBS scattering cross-section uncertainties cannot be correct in principle, although pragmatically it seems very helpful (provided a nuclear model is available to allow direct comparability of data for different scattering angles).

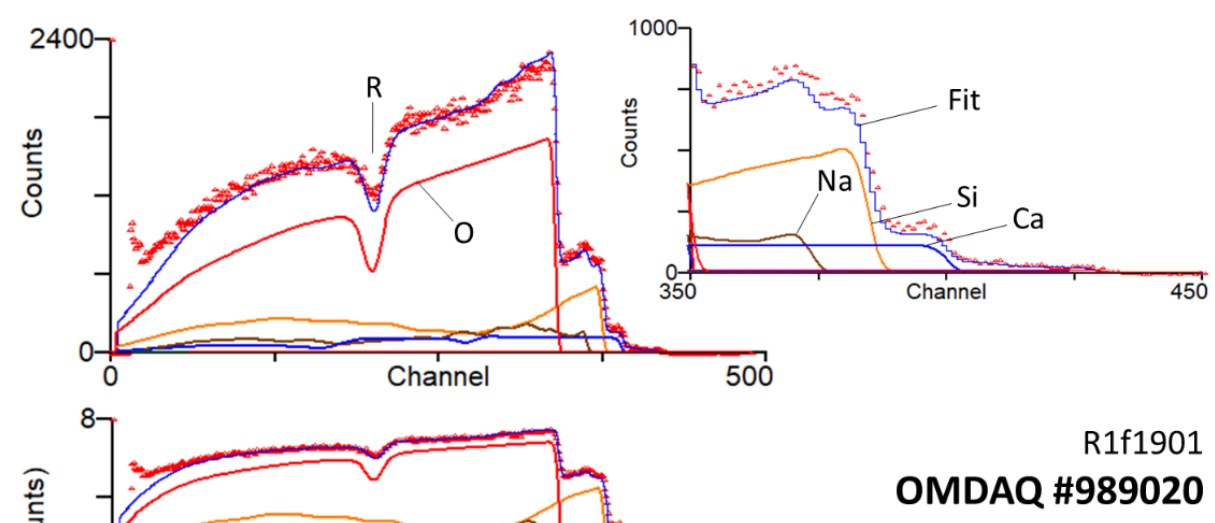

$\mathrm{SiO}_{2} / \mathrm{Na}_{2} \mathrm{O}=5.84$
$\mathrm{SiO}_{2} / \mathrm{Al}_{2} \mathrm{O}_{3}=109$
(from EPMA)

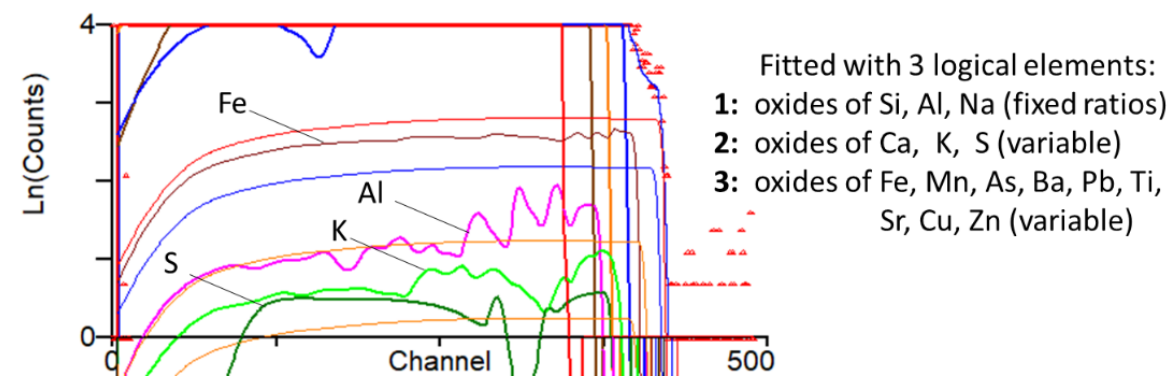

Figure 5a: Total-IBA of Rosslyn glass (particle spectrum)

Top (linear scale): EBS partial spectra are shown for $\mathrm{O}, \mathrm{Na}, \mathrm{Si}, \mathrm{Ca}$ (respectively purple, blue, orange, green).

Top (inset): detail of the EBS signal above the $\mathrm{O}$ edge. Centre \& bottom (natural log scale): EBS of minor elements Al, K, S (purple, green, dark green); RBS of minor elements $\mathrm{Pb}, \mathrm{Ba}, \mathrm{As}, \mathrm{Mn}$ (red, blue, orange, magenta)

Benchmark measurements are quite complicated, and so far they have not been used to underpin formal estimates of measurement uncertainties. They are usually used informally to give qualitative support for particular cross-sections, which is how they are presented on the SigmaCalc site (see Gurbich, 2016 [ref.49]): given a well-known sample, the particle scattering spectrum obtained 
should be the same as the spectrum simulated for those conditions, provided correct cross-sections are used. Pragmatically, the spectrum is calculated and if the match is reasonable then so are the cross-sections. Kokkoris et al. (2017) ${ }^{84}$ have helpfully quantified this judgment for $3 \mathrm{MeV}$ protons on $\mathrm{Si}$ and $\mathrm{O}$ at various scattering angles: we will use these results in Uncertainties.

Figure 5a can be regarded as a benchmark for the sum of all the scattering cross-section functions used since the sample is a) uniform and $b$ ) has a composition well-determined (prior to IBA) by EPMA. The point here is that the full interpretation of the EBS spectrum relies on mass closure since the energy loss of the material is sensitive to the average $\mathrm{Z}$ of the material, in just the same way (but more directly) that the photon scattering in XRF is sensitive to average $\mathrm{Z}$ as pointed out in 2016 by Perrett et al. [ref.76].

This means that the spectral misfit (see again Figure 5a), which is a function of how much in error the scattering cross-sections actually are, does not in this case determine the uncertainty in the average $\mathrm{Z}$. For in the present case, the spectrum is dominated by the $\mathrm{O}$ yield, but the $\mathrm{O}$ content is constrained by the assumption of full oxidation. That is, it is given unambiguously by the cation content of the glass. Therefore, the composition is known with a significantly lower uncertainty than would be assessed simply from the EBS misfit. The EBS spectra tell us, independently, both the composition and the error in the sum of the scattering cross-section functions (and also the charge-solid-angle product for this spectrum: although this is not independent of the average scattering cross-section it is nearly independent of the shape of the cross-section function). If we wished, DataFurnace could quantify the uncertainties in these parameters using the numerical methods (Markov chain Monte Carlo,

MCMC) central to the code. ${ }^{85}$ In the present case this would be somewhat misleading since we would obtain only the analysis precision which would look very high, being from a single dataset. We will estimate instead the analysis accuracy using more transparent and general methods.

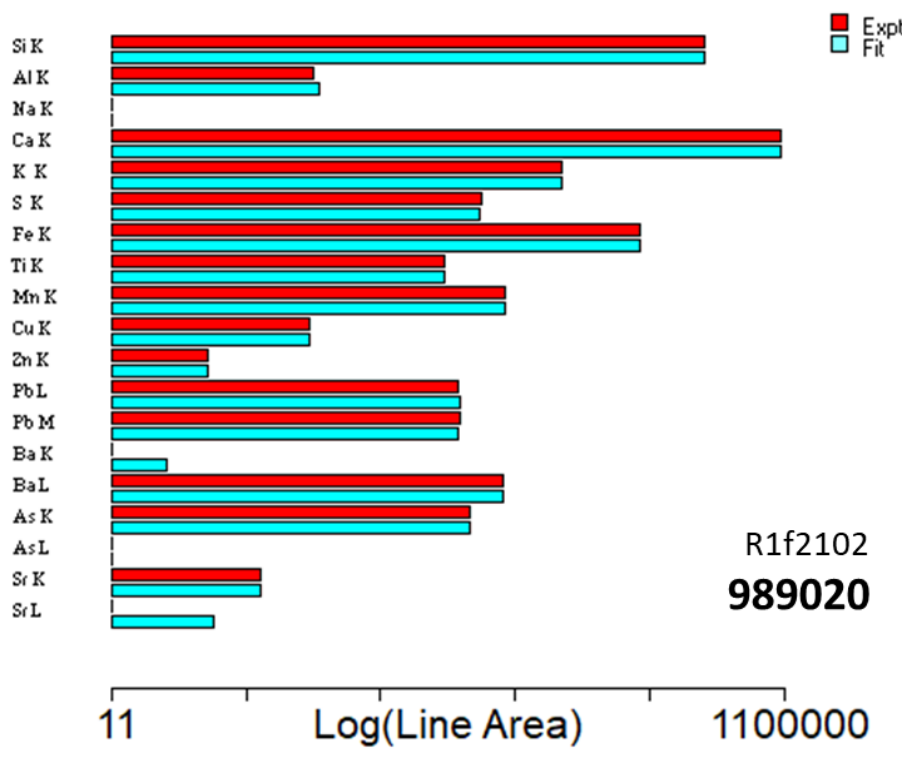

Figure 5b: Total-IBA of Rosslyn glass (PIXE data and fit)

\begin{tabular}{|l|llllllll|}
\hline \multirow{3}{*}{ mol\% } & $\mathbf{S i}$ & $\mathbf{A l}$ & $\mathbf{N a}$ & $\mathrm{Ca}$ & $\mathbf{K}$ & $\mathbf{S}$ & $\mathrm{Fe}$ & $\mathbf{0}$ \\
\cline { 2 - 9 } wt\% & 25.44 & 0.278 & 8.722 & 4.099 & 0.1194 & 0.1061 & 0.3195 & 60.74 \\
& 33.96 & 0.356 & 9.530 & 7.807 & 0.2219 & 0.1616 & 0.8479 & 46.18 \\
\cline { 2 - 9 } & $\mathrm{Ti}$ & $\mathrm{Mn}$ & $\mathrm{Cu}$ & $\mathrm{Zn}$ & $\mathbf{P b}$ & $\mathrm{Ba}$ & $\mathrm{As}$ & $\mathrm{Sr}$ \\
\cline { 2 - 9 } mol\% & 0.0152 & 0.0333 & 0.0013 & 0.0002 & 0.0328 & 0.0502 & 0.0421 & 0.0034 \\
wt\% & 0.0345 & 0.0822 & 0.0033 & 0.0007 & 0.3228 & 0.3274 & 0.1500 & 0.0141 \\
\hline
\end{tabular}

Table 6: Elemental bulk composition of Rosslyn glass 
The most important cross-section in the present work on glass is that for ${ }^{16} \mathrm{O}(\mathrm{p}, \mathrm{p}){ }^{16} \mathrm{O}$ since about $60 \%$ of the glass atoms are O. A nuclear model for this reaction was published in 1997 [ref.52] and the model parameters updated in 2001 (Table 2). Inspection of the 1997 paper shows that the model uncertainty at $3 \mathrm{MeV}$ appears to be low (probably $<2 \%$ ), and inspection of the benchmark measurements (Fig.11 of Kokkoris et al., 2017 [ref.84]) shows only $\sim 5 \%$ deviation at $\sim 3 \mathrm{MeV}$.

However, the next most abundant element is $\mathrm{Si}$, for which the cross-section data are much more uncertain. Figure 6 shows benchmark data for this reaction reworked from observations on a pure $\mathrm{Si}$ test sample made previously by Kokkoris et al (2017 [ref.84]).

A nuclear model for ${ }^{28} \mathrm{Si}(\mathrm{p}, \mathrm{p})^{28} \mathrm{Si}$ was published in 1998 [ref.55]. However, the benchmarks of Kokkoris et al (2017 [ref.84]) using these cross-sections show 22\% deviations for Si near $3 \mathrm{MeV}$ (see their Table 3 and Figs.5c, $6 \mathrm{~b}$ where simulations are below the data). The nuclear model parameters for the Si reaction were updated in 2017 (Table 2), and the benchmarks were recalculated (Figure 6) with significantly lower deviations. However, at $3080 \mathrm{keV}$ there remain deviations $\sim 10 \%$.

\section{Uncertainties}

Tables 7a, 7b give the measurement uncertainty from the counting statistics for the EBS and PIXE data respectively, together with the comparable reproducibility values for EPMA. We shall assume that the EPMA values represent the combined uncertainty fairly well, since the accuracy of this method for appropriate samples is recognised. But although a metrologically valid uncertainty budget has been published previously for RBS, ${ }^{86}$ and an uncertainty budget has recently been presented (for the first time) for measurements of certain XRF parameters [ref.4], no uncertainty budget has yet been presented either for EBS or for PIXE.

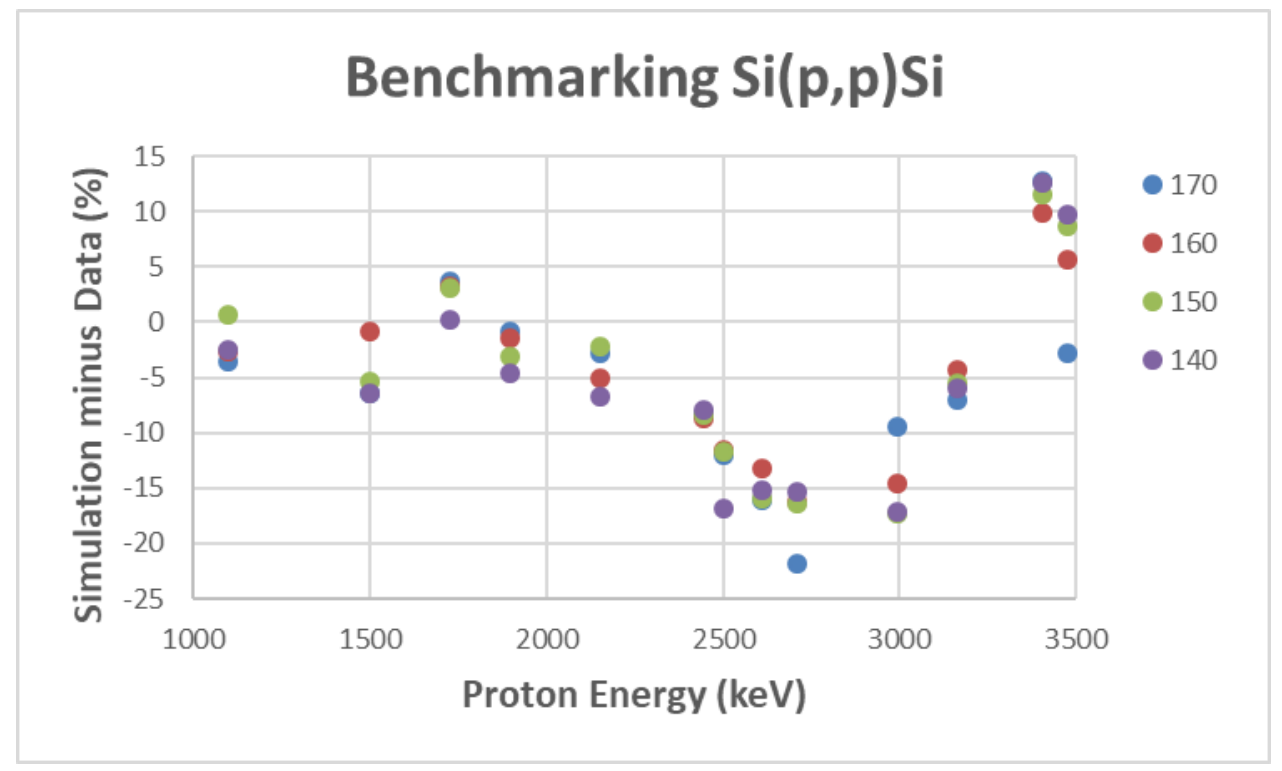

Figure 6: Comparing EBS data from pure Si with simulated spectra

${ }^{\text {nat }} \mathrm{Si}(\mathrm{p}, \mathrm{p})^{\mathrm{nat}} \mathrm{Si}$ scattering cross-sections from evaluation (SigmaCalc updated Feb. 2017). Various backscattering
angles $\left(140^{\circ}, 150^{\circ}, 160^{\circ}, 170^{\circ}\right)$ are used. Compare Fig.6 of Kokkoris et al, 2017 [ref.84]

For PIXE (and the other XRF techniques) the fundamental difficulty is in assessing the combined uncertainties of the multiple cross-section databases (ionisation, fluorescence yield, absorption) together with issues related to the excitation volume (for electron excitation) or energy loss crosssections (for ion excitation). A "bottom-up" analysis seems intractable, but "top-down" results are now well accepted. Indeed, it has been known for thirty years that XRF techniques (that is: XRF, 
EPMA and PIXE) are capable of high accuracy (1\%) analysis of flat homogenous thick target samples, provided good calibration standards are available. With proper calibrations of these methods, sub-1\% accuracy has been repeatedly demonstrated for homogeneous samples (Hutton \& Elliott, $1980^{87}$, Younis et al., 2017, ${ }^{88}$ Campbell et al., 2019 [ref.46]).

EPMA accuracy has been discussed at length quite recently (2002) by Peter Statham ${ }^{89}$, who wrote the basic papers in the 1980s (see discussion in Bailey et al., 2009 [ref.97]). This accuracy is absolute since the calibrations are general, determining the instrumental response (a spectrometer constant) as a function of X-ray energy. This is confirmed by the recent work on data collected by the Mars Rover: extra-terrestrial samples are intrisically unknown (that is, comparable samples cannot be identified, strictly speaking) but the authors demonstrate that the analysis accuracy is extraordinarily high. $^{90,91}$ Moreover, the apparent systematic calibration difference between K, L, and M lines (apparently necessitating separate response curves, seen here in Table 3) have been shown recently to be an artefact of the databases. ${ }^{92}$

In the present work, the EPMA is assumed to have this accuracy, but the PIXE is essentially uncalibrated (since Table 3 only specifies the calibration factor at about 10\%). We wish to know in what way the PIXE accuracy is determined by the EBS (and vice versa).

For EBS the difficulty is assessing the uncertainty of the scattering cross-section function, which has not yet been done satisfactorily (pace Mayer [ref.83] and Gai \& Gurbich [ref.82], see Benchmarking above). For RBS spectra, in the case where the composition of a uniform sample is required, most of the contribution to the uncertainty budget usually comes from the counting statistics, first demonstrated two decades ago in the case where the In content of InGaAs thin films was determined at $1 \%$ with a fully traceable estimate of the uncertainty. ${ }^{93}$ Where the information is in the spectral step heights, the stopping power uncertainties cancel out almost entirely. And it is because the scattering cross-sections are known analytically that RBS is so accurate.

\begin{tabular}{|c|c|c|c|c|c|}
\hline & \multicolumn{4}{|c|}{ EBS } & \multirow{2}{*}{$\begin{array}{l}\text { EPMA } \\
\text { accuracy }\end{array}$} \\
\hline & Rol & integral & background & precision & \\
\hline $\mathrm{Pb}$ & $412-430$ & 226 & 163 & $8.7 \%$ & \\
\hline $\mathrm{Fe}$ & & & & & $0.4 \%$ \\
\hline $\mathrm{Ca}$ & $390-400$ & 1106 & 455 & $3.6 \%$ & $0.5 \%$ \\
\hline Si & $375-383$ & 4369 & 1506 & $1.8 \%$ & $0.5 \%$ \\
\hline $\mathrm{Na}$ & $360-373$ & 1888 & 8700 & $5.4 \%$ & $1.7 \%$ \\
\hline 0 & $335-343$ & 14833 & 5762 & $1.0 \%$ & \\
\hline
\end{tabular}

Table 7a: EBS (and comparative EPMA) uncertainties for Rosslyn glass analysis

The integral (in counts) for the given elemental signal is given for the appropriate region of interest (RoI: see Figure 5a); the background signal in this RoI is also given, together with the relative standard uncertainty from the counting statistics (including the contribution from $\mathrm{O}$, see text). The relative standard uncertainty of the corresponding EPMA reproducibility is also given: see Table 4.

How can the composition uncertainty traceable to the EBS cross-section uncertainty in Figure 5a be characterised? Clearly the details of the spectrum depend heavily on the details of quite a large set of scattering cross-sections, each of which has a complicated functional shape with many parameters. Can any reasonable uncertainty be estimated? As for the XRF techniques, this problem is intractable to a "bottom-up" approach.

The sensitivity of the cross-section to scattering angle - at $150^{\circ}: 0.6 \% /^{\circ}$ for $\mathrm{O}(\mathrm{p}, \mathrm{p})$ and $2 \% /^{\circ}$ for $\mathrm{Si}(\mathrm{p}, \mathrm{p})$ - is given by the nuclear model (see Table 2 for references and updates). Tables 8 indicate the sensitivity to scattering angle of the interpretation of the steps in the EBS spectrum at the elemental edges (see Figure 5a). These steps directly give the composition of homogeneous samples, 
provided that the cross-sections are known. The cross-sections for various nuclei are given relative to Rutherford as a function of angle in Table 8a, and the consequent interpretation of a step height in the EBS spectrum as an elemental ratio is given in Table $\mathbf{8 b}$.

\begin{tabular}{|c|c|c|c|c|c|c|}
\hline \multirow[t]{2}{*}{ LineName } & \multirow{2}{*}{$\begin{array}{l}\text { Data } \\
\text { counts }\end{array}$} & \multirow{2}{*}{$\begin{array}{l}\text { Fit } \\
\text { counts }\end{array}$} & \multicolumn{3}{|c|}{ Uncertainty } & \multirow{2}{*}{$\begin{array}{c}\text { EPMA \% } \\
\text { Uncertainty }\end{array}$} \\
\hline & & & GUPIX \% & Misfit \% & Total \% & \\
\hline Si K & 285330 & 285107 & 1.0 & $0.1 \%$ & 2.1 & 0.5 \\
\hline Ca K & 1041700 & 1041650 & 0.2 & $0.0 \%$ & 3.7 & 0.5 \\
\hline K K & 25064 & 25057.6 & 1.6 & $0.0 \%$ & 4.0 & 1.7 \\
\hline S K & 6234 & 6149.1 & 4.8 & $1.4 \%$ & 6.1 & \\
\hline Fe K & 94466 & 94469.5 & 0.4 & $0.0 \%$ & 4.1 & 0.4 \\
\hline Ti K & 3355 & 3348.8 & 6.7 & $0.2 \%$ & 7.9 & \\
\hline Mn K & 9526 & 9527.8 & 1.7 & $0.0 \%$ & 4.5 & \\
\hline Cu K & 328 & 328 & 10.0 & $0.0 \%$ & 10.8 & \\
\hline Zn K & 58 & 57.9 & 38.3 & $0.2 \%$ & 38.5 & \\
\hline $\mathrm{Pb} \mathrm{L}$ & 4296 & 4368.8 & 3.6 & $1.7 \%$ & 5.5 & \\
\hline $\mathrm{Pb} \mathrm{M}$ & 4430 & 4169.2 & 8.5 & $6.3 \%$ & 9.5 & \\
\hline Ba L & 9082 & 9119.8 & 1.9 & $0.4 \%$ & 4.5 & \\
\hline As $K$ & 5130 & 5123.3 & 2.9 & $0.1 \%$ & 5.0 & \\
\hline Sr K & 142 & 142.3 & 14.3 & $0.2 \%$ & 14.9 & \\
\hline Al K & & 388.5 & 11.9 & & & 1.5 \\
\hline $\mathrm{NaK}$ & & 1.2 & & & & 1.7 \\
\hline
\end{tabular}

Table 7b: PIXE (and comparative EPMA) uncertainties for Rosslyn glass analysis

For OMDAQ dataset \#989020. The integral (in counts) for the given X-ray line is derived from GUPIX and given to NDF

("Data"); NDF "Fits" the data minimising the total misfit. The standard uncertainty per line from the counting statistics (including line overlaps) is obtained from GUPIX, with the "Misfit" (between Data and Fit) also given. The Total uncertainty is the quadrature sum of the GUPIX uncertainty and the appropriate EBS signal ratio uncertainty (from Table 7a: see text). The relative standard uncertainty of the corresponding EPMA reproducibility is copied from Table 7a.

\begin{tabular}{|l|c|cccccc|}
\hline & Beam & \multicolumn{6}{|c|}{ Scattering Angle } \\
\cline { 2 - 8 } & $\mathbf{M e V}$ & $\mathbf{1 5 0}^{\circ}$ & $\mathbf{1 5 5}^{\circ}$ & $\mathbf{1 6 0}^{\circ}$ & $\mathbf{1 6 5}^{\circ}$ & $\mathbf{1 7 0}^{\circ}$ & $\mathbf{1 7 5}^{\circ}$ \\
\hline $\mathbf{1 6 0}$ & 3.080 & 7.669 & 7.901 & 8.085 & 8.223 & 8.318 & 8.373 \\
natSi & 3.080 & 1.869 & 2.205 & 2.544 & 2.852 & 3.099 & 3.259 \\
$\mathbf{4 0 C a}$ & 2.920 & 1.249 & 1.280 & 1.307 & 1.329 & 1.346 & 1.356 \\
natFe & 3.081 & 0.992 & 0.998 & 1.004 & 1.008 & 1.011 & 1.013 \\
208Pb & & 1.000 & 1.000 & 1.000 & 1.000 & 1.000 & 1.000 \\
\hline
\end{tabular}

Table 8a: EBS cross-sections from proton beam relative to Rutherford from SigmaCalc 2.0

\begin{tabular}{|l|cc|c|cccccc|c|}
\hline \multicolumn{3}{|c|}{ EBS Step } & \multicolumn{8}{c|}{ Elemental Ratio } \\
\hline Element & counts & $\mathbf{\pm}$ & Rutherford & $\mathbf{1 5 0}^{\circ}$ & $\mathbf{1 5 5}^{\circ}$ & $\mathbf{1 6 0}^{\circ}$ & $\mathbf{1 6 5}^{\circ}$ & $\mathbf{1 7 0}^{\circ}$ & $\mathbf{1 7 5}$ & measured \\
\hline O/Si & 3.39 & $2.1 \%$ & 10.40 & 2.53 & 2.90 & 3.27 & 3.61 & 3.87 & 4.05 & $\mathbf{2 . 3 9}$ \\
$\mathbf{O} / \mathbf{C a}$ & 16.4 & $3.7 \%$ & 102.4 & 16.7 & 16.6 & 16.6 & 16.6 & 16.6 & 16.6 & $\mathbf{1 4 . 8}$ \\
$\mathbf{O} / \mathbf{P b}$ & 138 & $8.8 \%$ & 14532 & 1895 & 1839 & 1797 & 1767 & 1747 & 1736 & $\mathbf{1 8 5 3}$ \\
\hline
\end{tabular}

Table 8b: Spectral steps converted to elemental ratios for Rosslyn glass analysis

For OMDAQ dataset \#989020. Ratio of step heights (in counts, with counting statistics uncertainty from Table 7a) for data converted to elemental ratios from Table $\mathbf{8 a}$ and compared with measured values (at $3080 \mathrm{keV}$, from Table 6). Note that the $\mathrm{O} / \mathrm{Si}$ ratio is very sensitive to the scattering angle. The ratio for $\mathrm{RBS}$ at $150^{\circ}$ is also given. 


\begin{tabular}{|l|r|l|}
\hline \multicolumn{2}{|c|}{ Standard Uncertainty } & Comment \\
\hline Counting Statistics & $1.8 \%$ & From Table $\underline{7} \mathrm{a}$ \\
Angular (2 ${ }^{\circ}$ error) & $3.6 \%$ & From Table $\underline{8} \mathrm{~b}$ \\
Energy & $0.3 \%$ & From 2663 keV resonance \\
Random Uncertainty & $4.1 \%$ & \\
\hline Scattering cross-section & $10 \%$ & From Figure 6 \\
Combined Uncertainty & $10.8 \%$ & \\
\hline
\end{tabular}

Table 9: Simplified Uncertainty Budget for Si content by 3.08 MeV EBS

\begin{tabular}{|c|c|c|c|c|c|c|c|}
\hline & \multirow[t]{2}{*}{ mol\% } & \multicolumn{3}{|c|}{ Precision } & \multicolumn{2}{|c|}{ Accuracy } & \multirow[t]{2}{*}{ Comment } \\
\hline & & EBS & PIXE & Total-IBA & EPMA & Total-IBA & \\
\hline $\mathbf{0}$ & 60.7371 & $1.0 \%$ & & $1.0 \%$ & & & Chemical prior: assume oxides \\
\hline Si & 25.4415 & $1.8 \%$ & $1.0 \%$ & $0.9 \%$ & $0.5 \%$ & $2.0 \%$ & accuracy from EBS mass closure \\
\hline $\mathrm{Na}$ & 8.7218 & $5.4 \%$ & & $5.4 \%$ & $1.7 \%$ & $2.6 \%$ & accuracy from Si, fixed by EPMA \\
\hline $\mathrm{Ca}$ & 4.0988 & $3.6 \%$ & $0.2 \%$ & $0.2 \%$ & $0.5 \%$ & $3.3 \%$ & accuracy from $\mathrm{Ca} / \mathrm{Si}$ \\
\hline $\mathrm{Fe}$ & 0.3195 & & $8.8 \%$ & $8.8 \%$ & $0.4 \%$ & $10.6 \%$ & accuracy from $\mathrm{Pb}$ \\
\hline Al & 0.2775 & & & & $1.5 \%$ & $2.5 \%$ & accuracy from Si, fixed by EPMA \\
\hline K & 0.1194 & & $4.0 \%$ & $4.0 \%$ & $1.7 \%$ & $5.2 \%$ & accuracy from Ca \\
\hline $\mathbf{S}$ & 0.1061 & & $6.1 \%$ & $6.1 \%$ & & $6.9 \%$ & accuracy from Ca \\
\hline $\mathrm{Ba}$ & 0.0502 & & $9.0 \%$ & $9.0 \%$ & & $10.8 \%$ & accuracy from $\mathrm{Pb}$ \\
\hline As & 0.0421 & & $9.2 \%$ & $9.2 \%$ & & $11.0 \%$ & accuracy from $\mathrm{Pb}$ \\
\hline Mn & 0.0333 & & $8.9 \%$ & $8.9 \%$ & & $10.8 \%$ & accuracy from $\mathrm{Pb}$ \\
\hline $\mathbf{P b}$ & 0.0328 & $8.7 \%$ & $7.5 \%$ & $5.7 \%$ & & $6.0 \%$ & PIXE: L+M lines; accuracy from $\mathrm{Pb} / \mathrm{Si}$ \\
\hline Ti & 0.0152 & & $11.0 \%$ & $11.0 \%$ & & $12.6 \%$ & accuracy from $\mathrm{Pb}$ \\
\hline $\mathrm{Sr}$ & 0.0034 & & $16.8 \%$ & $16.8 \%$ & & $17.8 \%$ & accuracy from $\mathrm{Pb}$ \\
\hline $\mathrm{Cu}$ & 0.0013 & & $13.3 \%$ & $13.3 \%$ & & $14.6 \%$ & accuracy from $\mathrm{Pb}$ \\
\hline $\mathrm{Zn}$ & 0.0002 & & $39.3 \%$ & $39.3 \%$ & & $39.7 \%$ & accuracy from $\mathrm{Pb}$ \\
\hline sum & 100.0000 & & & & & & \\
\hline
\end{tabular}

Table 10: Accuracy of Total-IBA (see text)

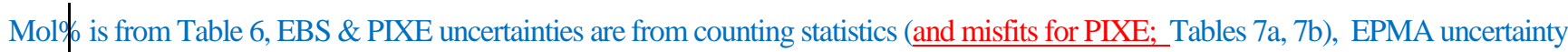
is from reproducibility (Table 7a). The Total-IBA Accuracy column is derived in various ways indicated by the Comments column: see text. Standard uncertainties are used throughout, and combined uncertainties are obtained simply by adding in quadrature.

However, athough the $\mathrm{O} / \mathrm{Si}$ ratio is sensitive to the scattering angle at about $2 \% /^{\circ}$ at $150^{\circ}$ as already mentioned (see Table 8b) there is a separate systematic and large uncertainty in the Si cross-section itself at this energy.

Table 9 summarises the contributions to the uncertainty of determining the Si signal height: this has a reproducibility dominated experimentally by the scattering angle uncertainty, but an absolute accuracy dominated by the uncertainty of the scattering cross-section itself at that energy. We use the benchmark calculations (Figure 6) to indicate a reasonable value of this latter dominating uncertainty. The uncertainty in the beam energy in this case is insignificant.

For this fit of the data, the PIXE data are fitted precisely (see Figure 5b). This means that the PIXE and EBS are consistent with each other considering the uncertainties, but that the fitting algorithm is able to give priority to the PIXE data since most of the elements visible in PIXE are either not well-determined or are entirely undetermined by EBS. However, the fact that the PIXE Si signal fits accurately means that the $151 \mu \mathrm{m}$ Be filter thickness (determined from the certified standard, Figure 3c) is determined correctly. Another way of putting this is to say that the calibration is confirmed. 
On the other hand, the PIXE calibration for $\mathrm{Ca}$ and $\mathrm{K}$ is clearly sensitive to geometry: the well-fitted $\mathrm{Ca}$ and $\mathrm{K}$ content in the BCR glass (see the H-factors in Table 3) is obtained using a sample tilt consistent with the EBS signal. The poorly fitted composition of the Rosslyn glass (see $\mathrm{Ca}$ and $\mathrm{K}$ in Table 5) may be an indication of a geometry error, although with less $\mathrm{Pb}$ content the sensitivity to this effect is smaller than for the BCR glass (the absorption edge of $\mathrm{Pb} \mathrm{M}$ is at $2.6 \mathrm{keV}$ and there is much more $\mathrm{Pb}$ in the lead-glass).

The $\mathrm{Pb}$ M calibration appears to vary by $20 \%$ between the BCR and Rosslyn glasses but this variation is consistent with the uncertainty of about $10 \%$ for the ratio of $\mathrm{Pb} \mathrm{L}$ to $\mathrm{Pb} \mathrm{M}$ (Table 7b).

Table 10 summarises the overall uncertainty of the analysis, giving an explicit account of how the accuracy is inherited. Uncertainties are combined in a simple-minded way since it is not obvious how to do this rigorously. We have here attempted to include neither energy nor geometry errors, nor the systematic calibration errors for PIXE, nor the errors due to incorrect scattering cross-sections for EBS. Moreover, Papp \& Maxwell (2017) show that counting statistics in PIXE are not Poisson, so that the usual $1 / \sqrt{ } \mathrm{N}$ measure may seriously underestimate the uncertainty. ${ }^{94}$

The "Accuracy" column in Table $\mathbf{1 0}$ does not include the systematic (calibration) uncertainties of PIXE, and is determined variously as indicated in the "Comments" column :-

1. The Si accuracy is determined independently (see Table 5) and is discussed extensively above in the context of the EBS Uncertainty Budget (Table 9). Note that Table 9 shows that the random uncertainty $(4 \%)$ is larger, and the systematic uncertainty $(10 \%)$ is much larger, than the $2 \%$ relative of Table 5 precisely because the chemical prior (that is, full oxidation of the cations) together with mass closure greatly reduce real uncertainties. This is the baseline uncertainty of the whole measurement.

2. For Na the Si accuracy is combined with the EPMA uncertainty: there is no measurable PIXE Na signal, and although there is an EBS Na signal this adds no information to the EPMA.

3. For $\mathrm{Al}$ the $\mathrm{Si}$ accuracy is combined with the EPMA uncertainty: there is no measurable $\mathrm{Al}$ signal for either EBS or PIXE.

4. For $\mathrm{Ca}$ the $\mathrm{Si}$ accuracy is combined with both EBS and PIXE uncertainties.

5. For $\mathrm{Pb}$ the $\mathrm{Si}$ accuracy is combined with both EBS and PIXE uncertainties, where the PIXE includes both the $\mathrm{L}$ and the $\mathrm{M}$ lines.

6. Uncertainties for the elements in LE2 (K, S) are combined from their PIXE uncertainty and the combined uncertainty for $\mathrm{Ca}$.

7. Uncertainties for the elements in $\mathrm{LE} 3(\mathrm{Fe}, \mathrm{Ti}, \mathrm{Mn}, \mathrm{Cu}, \mathrm{Zn}, \mathrm{Ba}, \mathrm{As}, \mathrm{Sr}$ ) are combined from their PIXE uncertainty and the combined uncertainty for $\mathrm{Pb}$.

Considering $\mathrm{Pb}$ as an example (\#5 in the list above) it is clear that where the accuracy from EBS cannot be better than $8.7 \%$ the Total-IBA accuracy inherits the accuracy of the PIXE $(6 \%)$ where this in turn (together with the whole analysis) rests on the accuracy of the the determination of Si content from EBS (\#1 in the list above), which depends on the mass closure criterion (see below). $\underline{\text { Inheritance is Discussed at length below. }}$

In this case, considering Figure 5a, the $\mathrm{O}$ signal appears too high near the $\mathrm{O}$ edge, and the cation signal appears systematically too low, as does the signal deeper than the resonance ("R"). Clearly, the charge- solid-angle product has been adjusted slightly to give an optimal $\chi^{2}$ fit over the whole spectrum. This may indicate that the ${ }^{16} \mathrm{O}(\mathrm{p}, \mathrm{p})^{16} \mathrm{O}$ scattering cross-sections are too high near $3 \mathrm{MeV}$. However, the benchmarking (Figure 6) makes it clear that the Si(p,p)Si scattering cross-sections are too low, which is probably sufficient to account for the discrepancy between IBA and EPMA in both the $\mathrm{Si}$ and the $\mathrm{Ca}$ (and hence $\mathrm{K}$ ) signals (see Table 5). 


\section{Mass Closure}

Table 9 shows the $4.1 \%$ EBS combined uncertainty of the Si signal, not including the uncertainty introduced by that of the EBS scattering cross-section for Si. The benchmark measurements shown in Figure 6 indicate that these cross-sections are underestimated by about $10 \%$ at this energy. The $\mathrm{Si}$ content of the glass (as silica) is given by Table 5. In this section we show that the $2 \%$ difference between IBA and EPMA shown for $\mathrm{Si}$ in Table 5 is much smaller than expected from a simple consideration of these uncertainties, and is a consequence of the mass closure constraint imposed by EBS together with the chemical prior of full oxidation.

It is clear that the underestimation of the EBS cross-section for Si has caused the Si content to be overestimated. But because this necessarily results in a consequent overestimation of the $\mathrm{O}$ content (since the Si only occurs as the oxide) both the $\mathrm{Si}$ and the $\mathrm{O}$ signals are too high. This is partially compensated by an arbitrary reduction in the assumed charge-solid-angle product (which is treated as a fitting parameter in this analysis). This is also partially compensated by a reduction in the $\mathrm{Ca}$ content: the relative concentrations of $\mathrm{Si}$ and $\mathrm{Ca}$ in the glass are given by Table $\mathbf{6}$ and the relative sensitivity of EBS to Si and Ca at this energy can be determined from Table $\mathbf{8 b}$. The spectral data for the Si/Ca ratio from EBS are given in Table 7a.

Indeed, Table 5 shows that IBA biasses the Si content high (because of the underestimated Si scattering cross-setcion) and therefore the Ca \& $\mathrm{K}$ content low (taking the EPMA composition as "true"). This is also partially because the PIXE data strongly constrains the Si/Ca ratio completely independently of EBS (the spectral data for the Si/Ca ratio from PIXE are given in Table $\mathbf{7 b}$ ). There may also be a further effect of an uncorrected sample tilt.

If there was no chemical prior for the glass composition, that is, if full oxidation was not assumed, then the $\mathrm{O}$ content would be an independent variable and in principle the total (combined) oxidation state of the sample could be measured independently. In practice, the derived value for the $\mathrm{O}$ content would be too sensitive to errors in the scattering cross-sections used to be useless for any but rather crude distinctions between oxidation states. Crucially, the derived cation content would also be very sensitive to errors in the scattering cross-sections.

Summarising, the mass closure properties of Total-IBA derive essentially from the EBS measurement and result in a significant improvement in absolute accuracy: they can be listed for clarity :-

1. The EBS signal is sensitive to the average $Z$ of the sample. This has long been recognised (see §5.3 in Jeynes et al., 2003 [ref.80]). Surprisingly, it is also true for XRF (not PIXE) spectra: the Guelph group has shown that the scatter peaks carry such information, which has been used to infer the existence of water on Mars (Perrett et al., 2016 [ref.76])

2. Mass closure means that all major and significant minor elements have measurable signal: this is specifically true for soda-lime glasses measured by EBS (as here: glasses and minerals with significant $\mathrm{Li}, \mathrm{B}, \mathrm{F}$ would need NRA, usually PIGE, for mass closure). $\mathrm{H}$ can be detected with ERD, but the presence of $\mathrm{H}$ can usually be ignored since the energy loss due to $\mathrm{H}$ is usually negligible.

3. Mass closure very strongly constrains the stoichiometry. This was already demonstrated implicitly in the accurate measurement by RBS of the In content of InGaAs samples [ref.93].

3.4. If the charge'solid-angle product and stopping cross-sections are known, then mass closure very strongly constrains the scattering cross-sections. In this in vacuo case (and in external beam systems such as the AGLAE facility ${ }^{95}$ in Paris) the solid-angle is an instrumental constant, and the charge can be effectively measured. And at present the scattering crosssections for $\mathrm{Si}$ at this proton energy are known to be significantly underestimated. 
4.5. The known oxidation state of glasses is a strong chemical prior for the EBS, providing extra information that (with mass closure) allows the charge-solid-angle product to be inferred. It also (independently) allows some limited correction of the scattering cross-sections. The value of the chemical prior was first cogently argued by Butler (1990), demonstrated for optical coatings by Jeynes et al., 2000 [ref.45], and discussed at length in both $\S 8.5$ of the Topical Review of 2003 [ref.80] and also §\$3.9, 4.2 of the Tutorial Review of 2016 [ref.1]).

5.6. PIXE does not have mass closure, but it does give an independent measure of elemental ratios. The systematic uncertainties for EBS (relating to scattering cross-section uncertainties) are unrelated to the systematic uncertainties for PIXE (involving the Fundamental Parameters databases which are mostly common between PIXE and XRF: for recent work on these see Unterumsberger et al., 2018 [ref.4]).

\section{Discussion}

In this work the samples are homogeneous in depth, which is the case GUPIX is designed to handle. However, NDF is used instead because NDF allows simultaneous (synergistic) treatment of the particle spectrum, and also because NDF supports general layered samples (needed in the wider study). The PIXE module of NDF uses LibCPIXE ${ }^{96}$ which is an independent code almost entirely equivalent to GUPIX (as shown by Bailey et al., 2009 ${ }^{97}$ )

PIXE and EPMA ought to be consistent with each other, since they differ only in the excitation mechanism. (Actually, the databases used are independent, as are the analytical codes.) The EPMA calibration method here is more detailed and more accurate: the PIXE calibration here uses only a single reference sample, and essentially fits only the filter thickness and average efficiency of the $\mathrm{X}$-ray detector to two main lines, where the other lines give a rough calibration $(\sim 10 \%)$ of the energy dependence of the efficiency.

The PIXE detector calibration from the BCR glass is well-behaved at $<10 \%$ precision. This calibration carries over successfully to the Rosslyn glass sample, where the main composition determined by Total-IBA is consistent (within the uncertainties) with the EPMA values (see Table 5).

In this case the pivot elements (for which precise signals are available both in EBS and in PIXE) are $\mathrm{Si}, \mathrm{Ca}, \mathrm{Pb}$. The values for these elements of the standard precision are respectively $\{2 \%, 4 \%, 9 \%\}$ for EBS (Table 7a) and $\{2 \%, 4 \%, 6 \%\}$ for PIXE (Table 7b). The present fitting code appears to give greater weight to the PIXE which is fitted perfectly, but that may largely be because the various $\mathrm{X}$-ray lines do not interact strongly (unlike the EBS signals). Even in this simplified case with a sample homogeneous with depth, the two datasets (PIXE, EBS) interact in complicated ways so that the covariance table is not simple to construct.

What has become very clear is that both the beam energy and the geometry must be closely controlled for reasonable accuracy. We can demonstrate that large mismatches for the $\mathrm{Ca}$ and $\mathrm{K}$ PIXE signals in Table 3 compared to EPMA can arise from quite small $\left(5^{\circ}\right)$ sample misorientations, consistent with the $5^{\circ}$ tilt value obtained from the behaviour of the $2663 \mathrm{keV}$ resonance in the EBS O signal (see Figure 3b).

But the largest contribution to uncertainty in EBS is due to the uncertain scattering cross-sections: the effect of these is the mismatch clearly visible above the $\mathrm{O}$ edge in the inset to Figure 5a. The benchmarking (see Figure 6) shows that the cross-sections for Si are low for this beam energy: therefore the Si content is forced high and consequently (because of mass closure) the Ca content is forced low (see the comparison with EPMA in Table 5). These data confirm the results of the benchmarks: it is a benchmark for the benchmarks. 
There are a number of intricate issues that remain unresolved. The $\chi^{2}$ fitting (even robustified) is suboptimal for PIXE, but it is not yet clear how to proceed correctly. The interplay between PIXE

and EBS (that is, which is given priority in the fitting) is uncontrolled, and at present is accidental in practice, depending on the numerical details. In principle this should be under the control of the analyst. The present algorithm does facilitate some control: in particular in the way the logical elements are set up (see Analytical Protocol), but more facilities are needed for more complex datasets.

\section{Conclusions}

\section{Conclusions regarding the analysis method:}

1. These measurements are of an homogeneous glass, which can be analysed unambiguously (but not necessarily completely) by any of EPMA, PIXE, EBS independently. In this case EPMA was of only 6 major and minor elements where 8 are present (S, $\mathrm{O}$ are not measured); PIXE is also sensitive to the 8 trace elements present (but major \& minor elements $\mathrm{Al}, \mathrm{Na}, \mathrm{O}$ were not measured); and EBS is sensitive to the major elements $(\mathrm{O}, \mathrm{Na}, \mathrm{Si}, \mathrm{Ca})$ and also the sum of these trace elements: $\{\mathrm{Pb}, \mathrm{Fe}, \mathrm{Ba}\}$.

2. A weathered glass has a modified surface layer: the depth profile cannot be obtained by EPMA, or by PIXE alone. But the Total-IBA measurements reported here for homogeneous glass (for which they are not necessary) generalise successfully to these other cases (for which they are indispensible).

3. Glasses cannot usually be analysed successfully by EBS which does not have sufficient mass resolution to account adequately for the many minor and trace elements. But EBS is an energy loss method and therefore sensitive to the average $\mathrm{Z}$ of the sample. Consequently, Total-IBA (where the minor and trace elements are determined by PIXE) has powerful mass closure properties, enabling a significantly higher accuracy than one might expect from a simple (but incorrect) assumption of independence of all the contributions to uncertainty.

4. In such complex analyses the beam energy and the sample geometry must be tightly controlled. Moreover, in EBS it is also necessary to use good scattering cross-sections even for minor elements.

5. Benchmarking shows that EBS scattering cross-sections for $\mathrm{Si}(\mathrm{p}, \mathrm{p}) \mathrm{Si}$ near $3 \mathrm{MeV}$ are about $10 \%$ too low. The present results are effectively a further and unequivocal benchmark for the previous benchmarking: they are actually quantifiable because the glass composition is known independently from EPMA. That the sample is not pure silicon is not necessarily a disadvantage since the more complex spectrum is able to fix most of the experimental parameters that contribute to the uncertainty in the simpler case.

6. It may be possible to use such glass samples to directly measure EBS cross-sections by the thick target inversion method, using the Bayesian inference facilities of DataFurnace as pioneered by Barradas et al. 2008. ${ }^{98}$

7. Sodium mobility under the beam does not preclude valid analysis in this case.

Conclusions regarding the analysis uncertainties:

1. The present EPMA measurements obtain the mass closure with $0.6 \%$ accuracy, independently confirmed by IBA demonstrating internal consistency of the EPMA/IBA analysis. Therefore the EPMA results are regarded here as "true", enabling the accuracy of the Total-IBA to be fairly assessed.

2. Synergistic Total-IBA measurements give a Si content with a deviation of only $2 \%$ from the EPMA result. This is in the context of intrinsic (rather uncertain) accuracies of $\sim 10 \%$ for both PIXE (calibration uncertainties) and EBS (cross-section uncertainties). This accuracy 
derives from the mass closure properties due to all the major elements being visible in the EBS spectra.

3. Measurements of individual elements show that accuracy is inherited from the most accurate technique, with the trace elements having PIXE accuracy and the major elements having EBS accuracy. The whole analysis is more accurate than expected from a simple uncertainty budget that neglects the powerful mass closure properties of EBS.

\section{Acknowledgements}

We acknowledge the support of the EPSRC (UK Engineering \& Physical Sciences Research Council) under contract NS/A000059/1. Thanks to Mark Bambrough (Scottish Glass Studios, Glasgow) and Rosslyn Chapel Trust for supplying stained glass pieces from the Rosslyn Chapel (near Edinburgh). Thanks to Prof. A. F. Gurbich (Obninsk) for help with SigmaCalc and information about it. Thanks to Dr. Paul Edwards (University of Strathclyde) for help with EPMA analyses, and to Dr. Thomas Calligaro (Paris) for helpful information on Na migration. We are grateful to the anonymous reviewer who stimulated a revision of the original to a very much better text.

\section{References}

1 C. Jeynes, J.L. Colaux, Tutorial Review: Thin film depth profiling by Ion Beam Analysis, Analyst 141 (2016) 5944-5985

2 C. Jeynes, N.P. Barradas, E. Szilágyi, Accurate determination of quantity of material in thin films by Rutherford backscattering spectrometry, Anal. Chem. 84 (2012) 6061-6069

3 C. Jeynes, RBS as a new primary direct reference method for measuring quantity of material, Nucl. Instrum. Methods Phys. Res., Sect. B, 2017, 406, 30-31

4 Rainer Unterumsberger, Philipp Hönicke, Julien L. Colaux, Chris Jeynes, Malte Wansleben, Matthias Müller and Burkhard Beckhoff, Accurate experimental determination of gallium K- and L3-shell XRF fundamental parameters, J. Anal. At. Spectrom., 2018, 33, 1003-1013

5 C. Jeynes, M. J. Bailey, N. J. Bright, M. E. Christopher, G. W. Grime, B. N. Jones, V. V. Palitsin and R. P. Webb, "Total IBA" - Where are we?, Nucl. Instrum. Methods Phys. Res., Sect. B, 2012, 271, 107-118

6 Ž. Šmit, M. Holc, Differential PIXE measurements of thin metal layers, Nuclear Instruments and Methods in Physics Research B 219-220 (2004) 524-529

7 C. Pascual-Izarra, N. P. Barradas, M. A. Reis, C. Jeynes, M. Menu, B. Lavedrine, J. Jacques Ezrati and S. Röhrs, Towards truly simultaneous PIXE and RBS analysis of layered objects in cultural heritage, Nucl. Instrum. Methods Phys. Res., Sect. B, 261 (2007) 426-429

8 T. F. Silva, C. L. Rodrigues, M. Mayer, M. V. Moro, G. F. Trindade, F. R. Aguirre, N. Added, M. A. Rizzutto and M. H. Tabacniks, MultiSIMNRA: A computational tool for self-consistent ion beam analysis using SIMNRA, Nucl.Instrum. Methods Phys. Res., Sect. B 371 (2016) 86-89

9 Mark Bambrough, Rosslyn Chapel: A Glazing History, The Journal of Stained Glass XXX, 2006 (Scotland Issue)

10 T. Calligaro, PIXE in the study of archaeological and historical glass, X-ray Spectrometry 37 (2008) 169-177

11 Myrtille O. J. Y. Hunault, Claudine Loisel, Fanny Bauchau, Quentin Lemasson, Claire Pacheco, Laurent Pichon, Brice Moignard, Karine Boulanger, Michel Hérold, Georges Calas, and Isabelle Pallot-Frossard, Nondestructive Redox Quantification Reveals Glassmaking of Rare French Gothic Stained Glasses, Analytical Chemistry 89 (2017) 6277-6284

12 Elzbieta Gurdak, Felicia M. Green, Paulina D. Rakowska, M.P. Seah, I.S.Gilmore; VAMAS Interlaboratory Study for Desorption Electrospray Ionization Mass Spectrometry (DESI MS) Intensity Repeatability and Constancy, Analytical Chemistry 86 (2014) 9603-9611

13 Alexander G. Shard, Rasmus Havelund, M. P. Seah, S. J. Spencer, I. S. Gilmore, N. Winograd, D. Mao, T. Miyayama, E. Niehuis, D. Rading, R. Moellers, Argon Cluster Ion Beams for Organic Depth Profiling: Results from a VAMAS Interlaboratory Study, Analytical Chemistry 84 (2012) 7865-7873 
14 M. P. Seah, Standards for surface analysis: a clash between bureaucracy and science? Philosophical Transactions of the Royal Society A 354 (1996) 2765-2780

15 V G Batanova, A V Sobolev, V Magnin, Trace element analysis by EPMA in geosciences: detection limit, precision and accuracy, IOP Conf. Series: Materials Science and Engineering 304 (2018) 012001

16 J.L.Campbell, N.I.Boyd, N.Grassi, P.Bonnick, J.A.Maxwell, The Guelph PIXE software package IV, Nucl. Instrum. Methods B, 268 (2010) 3356-3363

17 N. P. Barradas and C. Jeynes, "Advanced physics \& algorithms in the IBA DataFurnace", Nucl. Instrum Methods Phys. Res., Sect. B, 266 (2008) 1875-1879

18 A. Simon, C. Jeynes, R. P. Webb, R. Finnis, Z. Tabatabian, P. J. Sellin, M. B. H. Breese, D. F. Fellows, R. van den Broek and R. M. Gwilliam, The new Surrey ion beam analysis facility, Nucl. Instrum. Methods Phys. Res., Sect. B, 219 (2004) 405-409

19 M.J. Merchant, V.Palitsin, G.W. Grime, The use of the Wien filter to eliminate object slit scattering in MeV ion nanobeam systems, Nucl. Instrum. Methods Phys. Res., Sect. B, 267 (2009) 2021-2023

20 G.W. Grime, WinTRAX: A raytracing software package for the design of multipole focusing systems, Nucl. Instrum. Methods Phys. Res., Sect. B 306 (2013) 76-80

21 P.Mayaux, The certification of a lead glass BCR no.126 A and B (EUR 8137 EN), Commission of the European Communities; Community Bureau of Reference, 1982 (with Addendum: IRMM, Geel, 2009)

22 J.L. Colaux, G. Terwagne, C. Jeynes, On the traceably accurate voltage calibration of electrostatic accelerators, Nucl. Instrum. Methods B 349 (2015) 173-183

23 F.Ajzenberg-Selove, Energy levels of light nuclei A=16,17, Nuclear Physics A, 375 (1982) 1-168

24 R. A. Laubenstein and M. J. W. Laubenstein, Assignment of Angular Momenta to the Energy Levels of $\mathrm{F}^{17}$, Phys. Rev. 84 (1951) 18-28

25 V.Gomes, R.A.Douglas, T.Polga, O.Sala, The $\mathrm{E}_{\mathrm{p}}=2.66 \mathrm{MeV}$ resonance in $\mathrm{O}^{16}(\mathrm{p}, \mathrm{p}) \mathrm{O}^{16}$, Nuclear Physics A, 68 (1965) 417-425

26 G.W.Grime, M.Dawson, Recent developments in data acquisition and processing on the Oxford scanning proton microprobe, Nucl. Instr. Methods B, 104 (1995) 107-113

27 N. P. Barradas, C. Jeynes and R. P. Webb, Simulated annealing analysis of Rutherford backscattering data, Appl. Phys. Lett., 71 (1997) 291-293

28 C. Pascual-Izarra, M. A. Reis, N. P. Barradas, Simultaneous PIXE and RBS data analysis using Bayesian inference with the DataFurnace code, Nucl. Instrum. Methods Phys. Res., Sect. B, 2006, 249, 780-783

29 N. P. Barradas, R. Mateus, M. Fonseca, M. A. Reis, K. Lorenz and I. Vickridge, Thin film depth profiling using simultaneous particle backscattering and nuclear resonance profiling, Nucl. Instrum. Methods Phys. Res., Sect. B, 268 (2010) 1829-1832

30 J. F. Ziegler, M. D. Ziegler and J. P. Biersack, SRIM - The stopping and range of ions in matter, Nucl. Instrum. Methods Phys. Res., Sect. B 268 (2010) 1818-1823

31 Lucian Wielopolski, Robin P. Gardner, Prediction of the pulse-height spectral distortion caused by the peak pile-up effect, Nucl. Instrum. Methods 133, 1976, 303-309

32 U. Fasoli, E. A. Silverstein, D. Toniolo, G. Zago, The elastic scattering of protons by ${ }^{6} \mathrm{Li}$ in the energy range (1.3-5.6) MeV, Nuovo Cimento 34 (1964) 1832

33 P.R.Malmberg, Elastic scattering of protons from Li-7, Phys. Rev. 101 (1956) 114-118

34 R.Gleyvod, N.P.Heydenburg, M.Naqib, Elastic and inelastic scattering of protons by $\mathrm{Li}^{7}$, Nuc.Phys. 63 (1965) 650-656

35 A.Caciolli, G.Calzolai, M.Chiari, A.Climent-Font, G.Garcia, F.Lucarelli, S.Nava, Proton elastic scattering and proton induced $\gamma$-ray emission cross-sections on $\mathrm{Na}$ from 2 to $5 \mathrm{MeV}$, Nucl. Instrum. Methods Phys. Res., Sect. B, 266 (2008) 1392-1396

36 J. R. Vanhoy, E. G. Bilpuch, C. R. Westerfeldt, and G. E. Mitchell, Proton resonances in ${ }^{24} \mathrm{Mg}$ from $\mathrm{E}_{\mathrm{x}}=12.7$ to $15.7 \mathrm{MeV}$, Phys. Rev. C 36 (1987) 920-932

37 A.K.Valter, V.E.Storizhko, A.I.Popov, Elastic scattering of protons by Mg-24 nuclei, Soviet Physics JETPUSSR 17 (1963) 39-43

38 M. Chiari, L. Giuntini, P.A. Mandò, N. Taccetti, Proton elastic scattering cross-section on aluminium from 0.8 to $3 \mathrm{MeV}$, Nuclear Instruments and Methods in Physics Research B 174 (2001) 259-266

39 Zdravko Siketić, Iva Bogdanović Radović, N.Skukan, Milko Jakšić, Ana Rita Lopes Ramos, Proton elastic scattering from aluminum for $120^{\circ}, 150^{\circ}$ and $165^{\circ}$ [for energies] 2.4 to $5 \mathrm{MeV}$, Nucl. Instrum. Methods B 261 (2007) 414-417 
40 R.J.deMeijer, A.A.Sieders, H.A.A.Landman, G.deRoos, Investigation of proton-induced resonance reactions on ${ }^{39} \mathrm{~K}$, Nuclear Physics A 155 (1970) 109- 128

41 M. Kokkoris, A. Tsaris, P. Misaelides, D. Sokaras, A. Lagoyannis, S. Harissopulos, R. Vlastou, C.T.Papadopoulos, Determination of differential cross-sections for the ${ }^{\text {nat }} \mathrm{K}\left(\mathrm{p}, \mathrm{p}_{0}\right)$ and ${ }^{39} \mathrm{~K}\left(\mathrm{p}, \mathrm{\alpha}_{0}\right)$ reactions in the backscattering geometry, Nucl. Instrum. Methods B 268 (2010) 1797-1801

42 E.Koltay, L.Meskó, L.Végh, Levels of ${ }^{41} \mathrm{Sc}$ from the ${ }^{40} \mathrm{Ca}(\mathrm{p}, \mathrm{p}){ }^{40}$ Ca reaction, Nucl. Phys. A, 249 (1975) 173-181

43 W. N. Wang, E. K. Lin, and C. L. Tung, Differential Cross Sections for Elastic Scattering of Low-Energy Protons from ${ }^{24} \mathrm{Mg}$ and ${ }^{26} \mathrm{Mg}$, Chinese Journal of Physics 10 (1972) 1-6

44 F. Yang-Wallentin, K.G. Joreskog, H. Luo, Confirmatory factor analysis of ordinal variables with misspecified models, Struct. Equ. Model. 17 (2010) 392-423.

45 C. Jeynes, N.P. Barradas, H. Rafla-Yuan, B.P. Hichwa, R. Close, Accurate depth profiling of complex optical coatings, Surf. Interface Anal. 30 (2000) 237-242

46 J.L. Campbell, D.D. Thomson, E.L. Flannigan, N.G. Holmes, D.W. Tesselaar, S. VanBommel, A reexamination of the fundamental parameters approach to calibration of the Curiosity rover alpha particle Xray spectrometer, Nuclear Instruments \& Methods in Physics Research B 447 (2019) 22-29

47 H.H.Andersen, F.Besenbacher, P.Loftager, W.Möller, Large-angle scattering of light ions in the weakly screened Rutherford region, Phys.Rev.A, 21 (1980) 1891-1901

48 A.F.Gurbich, Evaluated differential cross-sections for IBA, Nucl. Instrum. Methods. B, 268 (2010) 1703-1710

49 A.F.Gurbich, SigmaCalc recent development and present status of the evaluated cross-sections for IBA, Nucl. Instrum. Methods Phys. Res., Sect. B, 371 (2016) 27-32

50 A.F.Gurbich, Evaluation of non-Rutherford proton elastic scattering cross-section for carbon, Nucl. Instrum. Methods Phys. Res., Sect. B 136-138 (1998) 60-5

51 D. Abriola, A.F.Gurbich, M.Kokkoris, A.Lagoyannis, V.Paneta, Proton elastic scattering differential crosssections for 12C, Nucl. Instrum. Methods B, 269 (2011) 2011-2016

52 A.F.Gurbich, Evaluation of non-Rutherford proton elastic scattering cross-section for oxygen, Nucl. Instrum. Methods Phys. Res., Sect. B 129 (1997) 311-6

53 A.F.Gurbich, C.Jeynes, Evaluation of non-Rutherford proton elastic scattering cross-section for magnesium, Nucl. Instrum. Methods B, 265 (2007) 447-452

54 A.F.Gurbich, N.P.Barradas, C.Jeynes, E.Wendler, Applying elastic backscattering spectrometry when the nuclear excitation function has a fine structure Nucl. Instrum. Methods. B 190 (2002) 237-40

55 A.F.Gurbich, Evaluation of non-Rutherford proton elastic scattering cross-section for silicon Nucl. Instrum. Methods Phys. Res., Sect. B 145 (1998) 578-8

56 A.F.Gurbich, Evaluation of the cross-section for elastic scattering of He-4 from carbon, Nucl. Instrum. Meth. B 161-163 (2000) 125-129

57 A.F.Gurbich and C. Jeynes, Evaluation of Non-Rutherford Alpha Elastic Scattering Cross-sections for Silicon, Nucl. Data Sheets, 119 (2014) 270-272

58 A. Abriola, P. Dimitriou, "Development of a Reference Database for Ion Beam Analysis", Report of a Coordinated Research Project (CRP) on Reference Database for Ion Beam Analysis

(IAEA-TECDOC-1780), Participants: N. P. Barradas, I. B. Radović, M. Chiari, A. F. Gurbich, C. Jeynes, M. Kokkoris, M. Mayer, A. R. Lopes Ramos, E. Rauhala and I. Vickridge, IAEA, Vienna, 2015

59 D. Abriola, N. P. Barradas, I. Bogdanović-Radović, M. Chiari, A. F. Gurbich, C. Jeynes, M. Kokkoris, M. Mayer, A. R. Ramos, L. Shi and I. Vickridge, Development of a reference database for Ion Beam Analysis and future perspectives, Nucl. Instrum. Methods Phys. Res., Sect. B, 269 (2011) 2972-2978

60 D.P.Lindstrom, H.W.Newson, E.G.Bilpuch, ,G.E.Mitchell, Fine structure of analogue states in ${ }^{55} \mathrm{Co},{ }^{57} \mathrm{Co}$ and ${ }^{59} \mathrm{Co}$, Nuclear Physics A 168 (1971) 37-55

61 M.J.Kenny, J.R.Bird, E.Clayton, Proton induced $\gamma$-ray yields, Nucl. Instrum. Methods 168 (1980) 115-120

62 I.Bogdanović, S.Fazinić, M.Jakšić, T.Tadić, O.Valković, V.Valković, Proton elastic scattering from fluorine, chlorine, zinc, selenium and bromine in the energy region from 2.5 to $4.8 \mathrm{MeV}$, Nuclear Instruments and Methods in Physics Research Section B 79 (1993) 524-526

63 G. Deconninck, G. Demortier, Thick-target excitation yields of prompt gamma-radiation from protonbombardment of Rh, Pd, Ag, Pt and Au, Journal of Radioanalytical Chemistry 24 (1975) 437-445

64 Vocabulaire international de métrologie; Joint Committee for Guides in Metrology, JCGM 200:2012 ( $3^{\text {rd }}$ edition: 2008 version with minor amendments), Bureau international des poids et mesures (BIPM) 
Guide to the Expression of Uncertainty in Measurement, Joint Committee for Guides in Metrology, JCGM 100:2008 (GUM 1995 with minor corrections), Bureau international des poids et mesures (BIPM)

66 K.A. Sjöland, F. Munnik, U. Wätjen, Uncertainty budget for Ion Beam Analysis, Nucl. Instrum. Methods B $\underline{161-163(2000) 275-280}$

67 D. Benzeggouta and I. Vickridge, Handbook on Best Practice for Minimising Beam Induced Damage during IBA, Cornell University Library, 2013, eprint arXiv:1303.3171

68 T.M.Walker, D.G.Howill, Field-Induced Migration of Sodium in Soda Silicate Glasses During Scanning Electron Microscopy, Scanning 11 (1989) 5-11 (doi: 10.1002/sca.4950110103)

69 G. Battaglin, G. Della Mea, G. de Marchi, P. Mazzoldi, A. Miotello, Alkali migration in ion irradiated glasses, Nuclear Instruments and Methods in Physics Research B I (1984) 511-515

70 G. Battaglin, G. Della Mea, G. De Marchi, P. Mazzoldi, Residence time before sodium migration in proton irradiated glasses, Applied Physics Letters 45 (1984) 736-738

71 P. March, F. Rauch, Hydration of soda-lime glasses studied by ion-induced nuclear reactions, Nuclear Instruments and Methods in Physics Research B, 15 (1986) 516-519

72 A.Carnera, G.Della Mea, A.V.Drigo, S.Lo Russo, P.Mazzoldi, Sodium surface concentration analysis on glass by ${ }^{23} \mathrm{Na}(\mathrm{p}, \alpha)^{20} \mathrm{Ne}$ nuclear reaction, Journal of Non-Crystalline Solids, 23 (1977) 123-128

73 M. Mosbah, J.-P. Duraud, Swift proton microbeam-induced di] 141 (1998) 594-599

74 Edward P. Vicenzi, Stephen Eggins, Amelia Logan and Richard Wysoczanski, Microbeam Characterization of Corning Archeological Reference Glasses: New Additions to the Smithsonian Microbeam Standard Collection, Journal of Research of the National Institute of Standards and Technology 107 (2002) 719-727

75 Michael Melcher, Rita Wiesinger, Manfred Schreiner, Degradation of Glass Artifacts: Application of Modern Surface Analytical Techniques, Accounts of Chemical Research 43 (2010) 916-926

76 Glynis M. Perrett, John L. Campbell, Ralf Gellert, Penelope L. King, Emily Nield, Joanne M. O’Meara, Irina Pradler, Refinement of the Compton-Rayleigh scatter ratio method for use on the Mars Science Laboratory alpha particle X-ray spectrometer: II - Extraction of invisible element content, Nuclear Instruments and Methods in Physics Research B 368 (2016) 129-137

77 K. Gotlib-Vainshtein, O. Girshevitz, V. Richter and C. N. Sukenik, Charging effects in the ion beam analysis of insulating polymers, Polymer, 72 (2015) 59-62

78 J. L. Campbell, Leonard McDonald, Theodore Hopman, Tibor Papp, Simulations of Si(Li) x-ray detector response, X-Ray Spectrometry 30 (2001) 230-241

79 J. L. Colaux and C. Jeynes, Accurate electronics calibration for particle backscattering spectrometry, Anal. Methods, 7 (2015) 3096-3104

80 C. Jeynes, N. P. Barradas, P. K. Marriott, G. Boudreault, M. Jenkin, E. Wendler and R. P. Webb,

Topical Review: Elemental thin film depth profiles by ion beam analysis using simulated annealing - a new tool, J. Phys. D: Appl. Phys., 36 (2003) R97-R126

81 V. Paneta, J.L. Colaux, A.F. Gurbich, C. Jeynes, M. Kokkoris, Benchmarking experiments for the proton backscattering on ${ }^{23} \mathrm{Na},{ }^{31} \mathrm{P}$ and ${ }^{\text {nat }} \mathrm{S}$ up to $3.5 \mathrm{MeV}$, Nucl. Instrum. Methods B 328 (2014) $1-7$

82 E.V. Gai, A.F. Gurbich, Evaluated ${ }^{12} \mathrm{C}\left({ }^{4} \mathrm{He},{ }^{4} \mathrm{He}\right){ }^{12} \mathrm{C}$ cross-section and its uncertainty, Nuclear Instruments and Methods in Physics Research B 296 (2013) 87-91

83 M. Mayer, Statistical analysis of cross-section data for ${ }^{12} \mathrm{C}\left({ }^{4} \mathrm{He},{ }^{4} \mathrm{He}\right){ }^{12} \mathrm{C}$ backscattering, Nuclear Instruments and Methods in Physics Research B 285 (2012) 116-124

84 M. Kokkoris, S. Dede, K. Kantre, A. Lagoyannis, E. Ntemou, V. Paneta, K. Preketes-Sigalas, G. Provatas, R. Vlastou, I. Bogdanović-Radović, Z. Siketić, N. Obajdin, Benchmarking the evaluated proton differential cross sections suitable for the EBS analysis of ${ }^{\text {nat }} \mathrm{Si}$ and ${ }^{16} \mathrm{O}$, Nucl. Instrum. Methods $\mathbf{4 0 5}$ (2017) 50-60

85 N. P. Barradas, C. Jeynes, M. Jenkin and P. K. Marriott, Bayesian error analysis of Rutherford backscattering spectra, Thin Solid Films 343 (1999) 31-34

86 Julien L. Colaux, Chris. Jeynes, Keith C. Heasman, Russell M. Gwilliam, Certified ion implantation fluence by high accuracy RBS, Analyst 140 (2015) 3251-3261

87 J.T.Hutton, S.M.Elliott, An accurate XRF method for the analysis of geochemical exploration samples for major and trace elements using one glass disc, Chemical Geology, 29 (1980) 1--11 
88 Adnan Younis, Zohrab Ahmadi, Matthew G. Adams and Amir Iqbal, A simple method for quantitative analysis of elements by WD-XRF using variable dilution factors in fusion bead technique for geologic specimens, X-Ray Spectrometry 46 (2017) 69 - 76

89 Peter J. Statham, Limitations to Accuracy in Extracting Characteristic Line Intensities From X-Ray Spectra, Journal of Research of the National Institute of Standards and Technology 107 (2002) 531-546

90 R. Gellert, B. C. Clark III and MSL MER Sci Teams, In Situ Compositional Measurements of Rocks and Soils with the Alpha Particle X-ray Spectrometer on Nasa's Mars Rovers, Elements, 2015, 11, 39-44

91 J. L. Campbell, G. M. Perrett, R. Gellert, S. M. Andrushenko, N. I. Boyd, J. A. Maxwell, P. L. King and C. D. M. Schofield, Calibration of the Mars Science Laboratory Alpha Particle X-ray Spectrometer, Space Sci.Rev., 2012, 170, 319-340

92 Erin L. Flannigan, Christopher M. Heirwegh, John L. Campbell, Role of the mass attenuation coefficient database in standardization of a silicon drift X-ray detector for PIXE analysis, X-Ray Spectrometry, 47 (2018) 63-71

93 C. Jeynes, Z. H. Jafri, R. P. Webb, A. C. Kimber and M. J. Ashwin, Accurate RBS measurements of the indium content of InGaAs thin films, Surf. Interface Anal., 1997, 25, 254-260

94 T. Papp, J.A. Maxwell, Is $\sqrt{ } \mathrm{N}$ a sufficient measure of the standard uncertainty in X-ray spectroscopy? $X$-Ray Spectrometry 46 (2017) 367-373

95 L.Pichon, B.Moignard, Q.Lemasson, C.Pacheco, P.Walter, Development of a multi-detector and a systematic imaging system on the AGLAE external beam, Nuclear Instruments and Methods in Physics Research B, 318 (2014) 27-31

96 C. Pascual-Izarra, N. P. Barradas and M. A. Reis, LibCPIXE: A PIXE simulation open-source library for multilayered samples, Nucl. Instrum. Methods Phys. Res., Sect. B, 249 (2006) 820-822

97 M.J.Bailey, S.Coe, D.M.Grant, G.W.Grime, C.Jeynes, Accurate determination of the Ca:P ratio in rough hydroxyapatite samples by SEM-EDS, PIXE and RBS - a comparative study, X-ray Spect. $\underline{38}$ (2009) 343-347

98 N.P. Barradas, A.R. Ramos, E. Alves, Determination of non-Rutherford cross-sections from simple RBS spectra using Bayesian inference data analysis, Nucl. Instrum. Methods Phys. Res. B 2008, 266, 1180-1184 


\section{${ }^{*}$ Conflict of Interest Forms}

\section{AUTHOR DECLARATION}

We wish to confirm that there are no known conflicts of interest associated with this publication and there has been no significant financial support for this work that could have influenced its outcome.

We confirm that the manuscript has been read and approved by all named authors and that there are no other persons who satisfied the criteria for authorship but are not listed.

We further confirm that the order of authors listed in the manuscript has been approved by all of us.

We confirm that we have given due consideration to the protection of intellectual property associated with this work and that there are no impediments to publication, including the timing of publication, with respect to intellectual property. In so doing we confirm that we have followed the regulations of our institutions concerning intellectual property.

We understand that the Corresponding Author is the sole contact for the Editorial process (including Editorial Manager and direct communications with the office). He/she is responsible for communicating with the other authors about progress, submissions of revisions and final approval of proofs. We confirm that we have provided a current, correct email address which is accessible by the Corresponding Author and which has been configured to accept email from (c.jeynes@surrey.ac.uk)

Approved by all authors as follows:

C.Jeynes (corresponding author, $11^{\text {th }}$ June 2019)

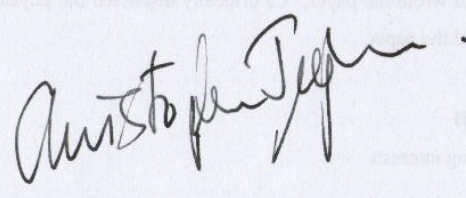

M.Kokkoris, $4^{\text {th }}$ June 2019

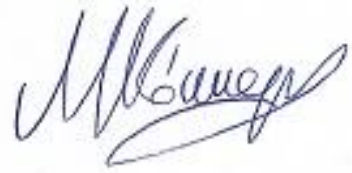

V.V.Palitsin, $12^{\text {th }}$ June 2019

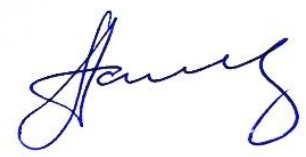

G.W.Grime, $16^{\text {th }}$ June 2019

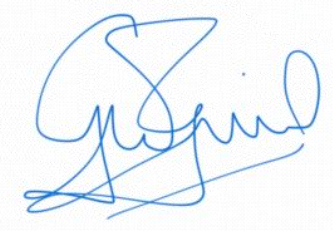

A.Hamilton, $15^{\text {th }}$ June 2019

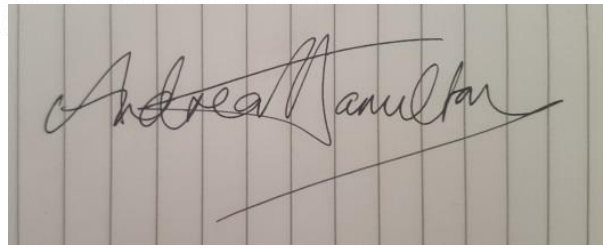




\section{Declaration of interests}

$\bigotimes$ The authors declare that they have no known competing financial interests or personal relationships that could have appeared to influence the work reported in this paper.

$\square$ The authors declare the following financial interests/personal relationships which may be considered as potential competing interests:

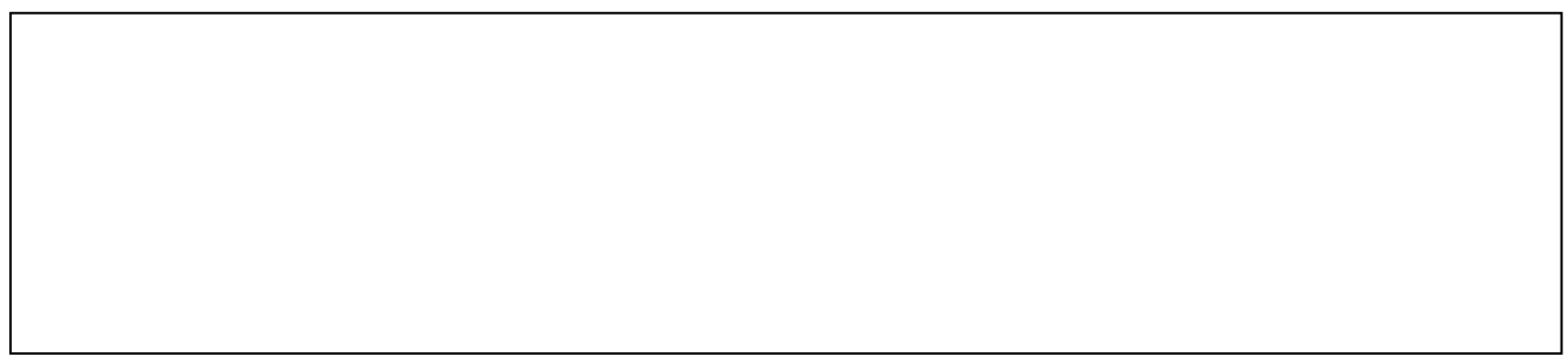




\section{Author Contribution Statement}

CJ Conceptualization; Data curation; Formal analysis; Funding acquisition; Methodology; Project administration; Resources; Software; Supervision; Validation; Visualization; Writing - original draft; Writing - review \& editing.

VVP Investigation; Resources; Software; Writing - review \& editing.

MK Data curation; Formal analysis; Investigation; Methodology; Resources; Validation; Visualization; Writing - review \& editing.

AH Conceptualization; Data curation; Formal analysis; Investigation; Methodology; Resources; Writing - review \& editing.

GWG Data curation; Formal analysis; Investigation; Resources; Software; 